\title{
ARTICLE \\ NGF sensitizes TrkA SH-SY5Y neuroblastoma cells to TRAIL-induced apoptosis
}

\author{
P Ruggeri ${ }^{1,2}$, L Cappabianca $^{1,2}$, AR Farina ${ }^{1}$, L Gneo $^{1}$ and AR Mackay ${ }^{1}$
}

We report a novel pro-apoptotic function for nerve growth factor (NGF) and its tropomyosin-related kinase A (TrkA) receptor in sensitizing TRAIL (TNF-related apoptotis-inducing ligand)-resistant SH-SY5Y neuroblastoma (NB) cells to TRAIL-induced apoptosis, resulting in the abrogation of anchorage-independent tumourigenic growth in vitro. We show that the TRAIL-resistant SH-SY5Y phenotype is CFLIP (cellular FLICE-like inhibitory protein) dependent and not due to low-level functional TRAIL receptor or caspase expression or an inhibitory equilibrium between functional and decoy TRAIL receptors or B-cell lymphoma 2 (Bcl-2) and BH3-only (Bcl-2 homology domain 3-only) family proteins. NGF sensitization of SH-SY5Y cells to TRAIL-induced apoptosis was dependent upon TrkA expression, activation and subsequent sequestration of cFLIP. This reduces cFLIP recruitment to TRAIL-activated death receptors and increases the recruitment of caspase-8, leading to TRAIL-induced, caspase-dependent, type II apoptosis via the intrinsic mitochondrial pathway. This effect was temporary, inhibited within $6 \mathrm{~h}$ by nuclear factor- $\kappa$ binding (NF- $\kappa \mathrm{B}$ )-mediated increase in myeloid cell leukaemia-1 ( $\mathrm{Mcl}-1)$ expression, abrogated by transient $\mathrm{CFLIP}$ or B-cell lymphoma-extra large (Bcl-xL) overexpression and optimized by NF-KB and Mcl-1 inhibitors. This novel mechanism adds an important pro-apoptotic immunological dimension to NGF/TrkA interaction that may not only help to explain the association between TrkA expression, better prognosis and spontaneous remission in NB, but also provides a novel potential pro-apoptotic therapeutic use for NGF, TRAIL and inhibitors of NF-KB and/or Mcl-1 in favourable and unfavourable NBs that express TrkA and exhibit CFLIP-mediated TRAIL resistance.

Cell Death Discovery (2016) 2, 16004; doi:10.1038/cddiscovery.2016.4; published online 1 February 2016

\section{INTRODUCTION}

During sympathetic nervous system (SNS) development, neuroblasts delaminate from the neural crest and migrate to form paraaortic sympathetic ganglia before differentiating into the various cellular components of the SNS. This finely tuned process is associated with both resistance and sensitivity to apoptosis, ensuring sufficient cell numbers to form the fully functional SNS, while eliminating cellular excess. Within this context, neuroblast resistance and sensitivity to apoptosis is regulated by neurotrophins (nerve growth factor (NGF), BDNF, NT3 and NT4/5) and their corresponding receptors (tropomyosin-related kinase (Trk)-A, TrkB, TrkC, p75 NTR and Sortilin). Active neurotrophins ligate TrkA, TrkB and TrkC to protect neuroblasts from apoptosis; TrkC in the absence of $\mathrm{p} 75^{\mathrm{NTR}}$ and TrkA in the presence of $\mathrm{p} 75^{\mathrm{NTR}}$ are proapoptotic in the absence of active neurotrophins, whereas $\mathrm{p} 75^{\mathrm{NTR}}$ and Sortilin are pro-apoptotic upon pro-neurotrophin ligation in the absence of Trk receptor expression. This variety of potential pro- and anti-apoptotic outcomes is regulated by spatial and temporal changes in neurotrophin and neurotrophin receptor expression. ${ }^{1}$

Apoptosis is activated via the extrinsic and/or intrinsic pathways. $^{2,3}$ The identification of tumour necrosis factor-a (TNFa) as the pro-apoptotic cytokine responsible for endotoxin-induced tumour necrosis ${ }^{4}$ paved the way for characterization of the extrinsic pathway and the subsequent identification of the TNFa pro-apoptotic cytokine family comprising TNFa, Apo1/Fas, Apo2L/TRAIL (TNF-related apoptotis-inducing ligand) and Apo3L that induce two types of apoptotic response through their cognate TNFR1, Apo1/FasL, FasR, Apo3L/DR3, Apo2L/DR4 and DR5 death receptors. ${ }^{5,6}$ In type I cells, activated death receptors recruit FADD (Fas-associated protein with death domain) and caspase-8 (or caspase-10) to induce apoptosis via the activation of caspase-7 and caspase-3. In type II cells, low-level caspase-8 activation does not result in the direct activation of caspase- 3 but cleaves the pro-apoptotic $\mathrm{BH} 3$-only $(\mathrm{BCl}-2$ homology domain 3-only) protein $\mathrm{BID}$ (BH3 interacting domain death agonist). Cleaved tBID translocates to the mitochondria and induces permeabilization of the outer mitochondrial membrane (OMM). This results in the release of the pro-apoptotic mitochondrial proteins cytochrome C, Omi/Htr2a and SMAC/DIABLO (second mitochondria-derived activator of caspases) into the cytosol that results in caspase-3-dependent apoptosis ${ }^{3,7}$ and/or caspaseindependent death through the release of mitochondrial apoptosis-inducing factors (AIFs) and endonuclease $\mathrm{G}^{8}$

Apo2L/TRAIL is a promising chemotherapeutic agent because of its selective pro-apoptotic action on tumour but not nontransformed cells ${ }^{9-12}$ that exhibit a multiplicity of redundant TRAIL resistance pathways. ${ }^{13}$ In tumour cells, TRAIL induces apoptosis by ligating functional DR4 and/or DR5 TRAIL receptors that recruit FADD and initiator caspase-8 (or -10) to the death-inducing complex DISC. ${ }^{5,6,14}$ In both type I and type 2 tumour cells, TRAILinduced apoptosis is regulated by the equilibrium between functional (DR4 and DR5) and decoy (DcR1, DcR2 and OPG) TRAIL receptors, the level of caspase-3, caspase-8, caspase-9 and

\footnotetext{
${ }^{1}$ Department of Applied Clinical and Biotechnological Sciences, University of L'Aquila, Via Vetoio, Coppito 2, L'Aquila 67100, Italy.

Correspondence: AR Mackay (andrewreay.mackay@univaq.it)

${ }^{2}$ These authors contributed equally to this work.

Received 4 December 2015; accepted 4 December 2015; Edited by G Melino
} 
caspase-10 expression and the equilibrium between caspase- 8 and its inhibitory analogues CFLIP-S and CFLIP-L. In type 2 but not type I cells, TRAIL-induced apoptosis is also regulated by the equilibrium between pro-apoptotic BH3-only and anti-apoptotic B-cell lymphoma $2(\mathrm{Bcl}-2)$ family proteins that regulate OMM permeability. 2,3,5-9,15

Neuroblastoma (NB) originates from neural crest-derived neuroblasts transformed at different stages along the sympathoadrenal lineage, blocked in differentiation and selected for resistance to apoptosis by a combination of oncogene activation, oncosuppressor inactivation and physiological apoptosis protection mechanism(s) conserved at the time of transformation. ${ }^{1}$ The characterization of these mechanisms is critical for developing novel pro-apoptotic therapeutic strategies.

The therapeutic application of TRAIL in NB has been hampered by reports of TRAIL resistance in NB cell lines and models, ${ }^{16-30}$ attributed to methylation-mediated caspase-8 silencing, altered expression of decoy and functional TRAIL receptors, high-level expression of CFLIP-S and/or CFLIP-L and protective IP3K/Akt/mTor and/or RIP/NF- $\kappa B$ signalling that promote an anti-apoptotic equilibrium between pro-apoptotic $\mathrm{BH} 3$-only and anti-apoptotic Bcl-2 family proteins. ${ }^{19-30}$ Sensitization of NB cells to TRAILinduced apoptosis has been reported for demethylating agents that increase caspase-8 expression; DR5 TRAIL receptor transduction, cFLIP (cellular FLICE-like inhibitory protein) and nuclear factor- $\kappa$ binding (NF- $K \mathrm{~B}$ ) inhibitors and drugs that promote a proapoptotic patterns of TRAIL-induced apoptosis component expression. $^{18,20,28,29,31-40}$

In the present study, we characterize a novel mechanism for sensitizing SH-SY5Y NB cells to TRAIL-induced apoptosis that involves NGF and its receptor TrkA. This novel mechanism not only adds a pro-apoptotic immunological dimension to NGF/TrkA interaction in neuroblasts but also provides a novel potential proapoptotic therapeutic strategy for the use of NGF and TRAIL in TrkA-expressing NB.

\section{RESULTS}

NGF sensitizes TRAIL-resistant TrkA SH-SY5Y cells to TRAIL-induced apoptosis

In two-dimensional culture, TRAIL at concentrations from $10 \mathrm{ng}$ to $1 \mu \mathrm{g} / \mathrm{ml}$ did not induce significant death of either nontransfected (NT), duplicate empty pcDNA3.1 vector (pcDNA)-transfected or duplicate TrkA-transfected SH-SY5Y cell lines, confirming their TRAIL-resistant phenotypes (Figures $1 \mathrm{a}$ and b). NGF $(100 \mathrm{ng} / \mathrm{ml})$ also failed to induce significant death of NT SH-SY5Y, pCDNA SH-SY5Y or TrkA SH-SY5Y cells (Figures $1 \mathrm{a}$ and b). In contrast, the combination of NGF $(100 \mathrm{ng} / \mathrm{ml})$ and TRAIL $(200 \mathrm{ng} / \mathrm{ml})$ induced a mean ( \pm S.D.) of $68.7 \pm 13.8$ and $66 \pm 14.3 \%$ death in the two TrkA SH-SY5Y cell lines but did not induce the death of either NT SH-SY5Y or pcDNA SH-SY5Y cells (Figures $1 \mathrm{a}$ and b). TrkA SH-SY5Y cells that survived the effects of NGF plus TRAIL exhibited neuritelike projections, suggesting the initiation of neural differentiation (Figure 1c). In concentration studies, the death of TrkA SH-SY5Y cells in the presence of NGF $(100 \mathrm{ng} / \mathrm{ml})$ was detected at TRAIL concentrations $\geq 50 \mathrm{ng} / \mathrm{ml}$ and plateaued with a mean ( \pm S.D.) of $68.3 \pm 15.3 \%$ death at a concentration of $200 \mathrm{ng} / \mathrm{ml}$ (Figures $1 \mathrm{a}$ and d). The TRAIL-induced death of TrkA SH-SY5Y cells was confirmed to be apoptotic by Tunel assay (Figure 1a), detection of DNA laddering (Figure 1e) and was abrogated by the caspase inhibitors z-DEVD-fmk (caspase-3), z-IETD-fmk (caspase-8) and z-LEHD-fmk (caspase-9) (see Figures $4 d$ and e).

\section{NGF/TRAIL inhibits TrkA SH-SY5Y tumourigenic growth in vitro}

The effect of TRAIL and NGF upon the tumourigenic activity of NT, pcDNA and TrkA SH-SY5Y cell lines was assessed in substrateindependent tumourigenesis assays in vitro.
NT, pcDNA and TrkA SH-SY5Y cells formed similar numbers of similar-sized tumour spheroids over 14 days in soft agar tumourigenesis assays, under basal conditions (Figures 2a and b, identical results were obtained for duplicate cell lines and results are displayed for single NT, pcDNA and TrkA SH-SY5Y cell lines). The addition of TRAIL $(200 \mathrm{ng} / \mathrm{ml})$ to soft agar did not significantly reduce the tumourigenic activity of NT SH-SY5Y, pCDNA SH-SY5Y or TrkA SH-SY5Y cells (Figures $2 \mathrm{a}$ and b). NGF $(100 \mathrm{ng} / \mathrm{ml}$ ) added to soft agar significantly reduced the number of tumour spheroids formed by TrkA SH-SY5Y cells by a mean ( \pm S.D.) of $58.5 \pm 9.1 \%$ $(P<0.0001$, d.f. $=10)$ but did not inhibit the number of tumour spheroids formed by either NT SH-SY5Y or pcDNA SH-SY5Y cells over 14 days (Figures $2 \mathrm{a}$ and $\mathrm{b}$ ). Furthermore, tumour spheroids formed by TrkA SH-SY5Y cells in the presence of NGF $(100 \mathrm{ng} / \mathrm{ml})$ appeared to be less well formed (Figure 2c). The addition of NGF $(100 \mathrm{ng} / \mathrm{ml})$ plus TRAIL $(200 \mathrm{ng} / \mathrm{ml})$ to soft agar abrogated tumour spheroid growth by TrkA SH-SY5Y cells, resulting in a mean ( \pm S.D.) of $96.8 \%(P<0.0001$, d.f. $=10)$ inhibition when compared with untreated TrkA SH-SY5Y cells and 92.5\% $(P<0.0001$, d.f. $=10)$ inhibition when compared with NGF-treated TrkA SH-SY5Y cells (Figures $2 \mathrm{a}$ and $\mathrm{b}$ ). In contrast, the combination of NGF plus TRAIL did not reduce the number of tumour spheroids formed by NT SH-SY5Y or pcDNA SH-SY5Y cells (Figures 2a and b).

SH-SY5Y cells express all components required for TRAIL-induced apoptosis

Molecular characterization of the TRAIL-resistant SH-SY5Y phenotype revealed similar levels of constitutive mRNA and protein expression for functional (DR4 and DR5) and decoy (DcR1 and DCR2) TRAIL receptors; caspase-3, caspase-8 and caspase-9; cFLIP-S and CFLIP-L; BCl-2, B-cell lymphoma-extra large (BCl-xL), myeloid cell leukaemia-1 (Mcl-I) and BID in NT SH-SY5Y, pcDNA SH-SY5Y and TrkA SH-SY5Y cell lines (Figures $3 a$ and $b$, identical results were obtained for duplicate cell lines and results are displayed for single NT, PCDNA and TrkA SH-SY5Y cell lines). Indirect IF confirmed similar levels of DR4, DR5, DCR1 and DCR2 TRAIL receptors in NT SH-SY5Y, pcDNA SH-SY5Y and TrkA SH-SY5Y cells, with an equilibrium in favour of functional rather than decoy receptors. Indirect IF confirmed cell surface DR4 and DR5 receptor expression in nonpermeabilized cells (Figure 3c). In TrkA SH-SY5Y cells, NGF (100 ng/ml for 3 and $6 \mathrm{~h}$ ) alone increased the expression of $\mathrm{Mcl}-1, \mathrm{Bcl}-\mathrm{xL}$ and DR5, decreased DcR2 expression, did not alter the expression of DR4, DcR1, caspase-3, caspase-8, caspase-9, CFLIP-S, CFLIP-L, Bcl-2 or BID and did not regulate the expression of any of these genes in either NT SH-SY5Y or PcDNA SH-SY5Y cells (Figures $4 a$ and $b$, data displayed for TrkA SH-SY5Y cells only). TRAIL ( $200 \mathrm{ng} / \mathrm{ml}$ for 3 and $6 \mathrm{~h}$ ) alone did not alter the expression of these genes in NT SH-SY5Y, pcDNA SH-SY5Y or TrkA SH-SY5Y cells (data not displayed). These data indicate that the TRAILresistant SH-SY5Y phenotype does not result from a lack of expression of any single component of TRAIL-induced apoptosis; TrkA per se does not alter the expression of components of TRAILinduced apoptosis in SH-SY5Y cells and NGF stimulates Mcl-1 and to a lesser extent BCl-xL, DR4 and DR5 expression in TrkA SH-SY5Y cells.

NGF plus TRAIL induce type II apoptosis in TrkA SH-SY5Y cells TRAIL-induced apoptosis of NGF-sensitized TrkA SH-SY5Y cells was associated with the cleavage of BID, caspase-3, caspase-8 and caspase-9, increased cytosolic levels of the mitochondrial proteins cytochrome $\mathrm{C}$ and $\mathrm{Htr} 2 \mathrm{a} / \mathrm{OMI}$ and reduced cytosolic levels of the caspase inhibitor XIAP (X-linked inhibitor of apoptosis) (Figure 4c, results displayed for a single TrkA SH-SY5Y cell line only). The caspase-3 inhibitor z-DEVD-fmk $(100 \mu \mathrm{M})$, caspase-8 inhibitor z-IETD-fmk $(20 \mu \mathrm{M})$ and the capase-9 inhibitor z-LEHD $(50 \mu \mathrm{M})$ all significantly inhibited TRAIL-induced apoptosis of NGF-sensitized TrkA SH-SY5Y cells (Figure $4 d$ ) from a mean ( \pm S.D.) of $73.2 \pm 17 \%$ in untreated controls to $10 \pm 18 \%(P<0.0001$, d.f. $=10), 12 \pm 16.3 \%$ 
a

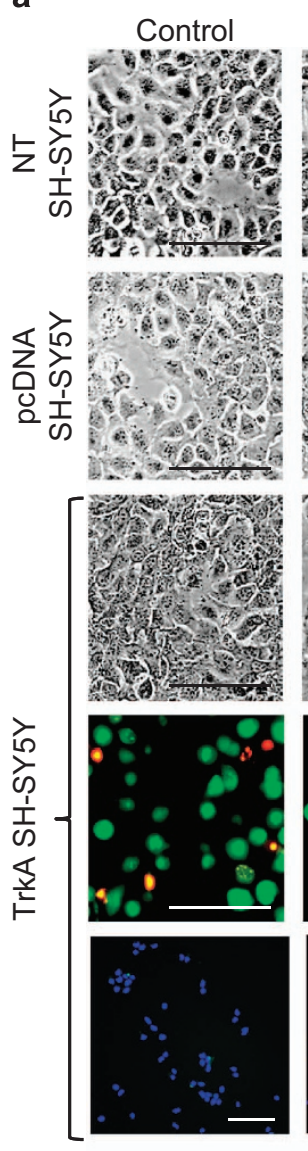

NGF
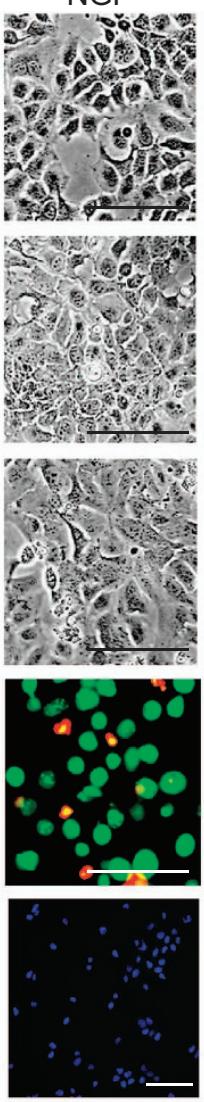

TRAIL
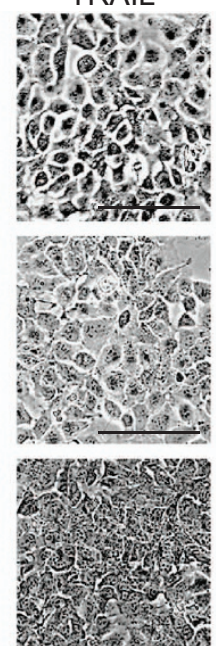

NGF/TRAIL
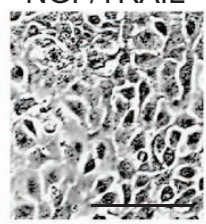

1.
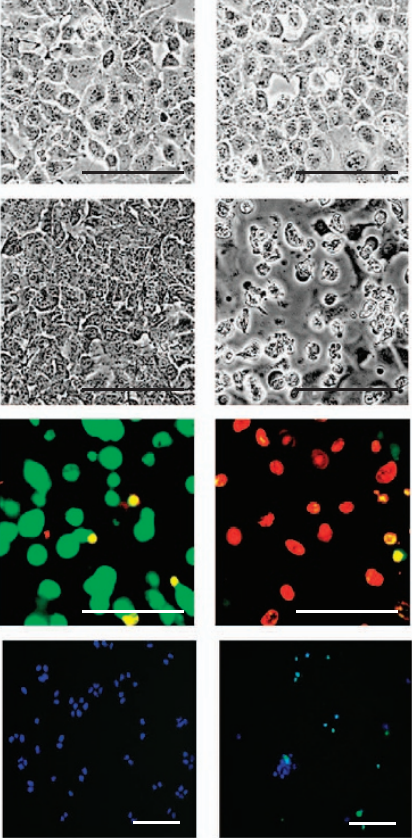

C Control

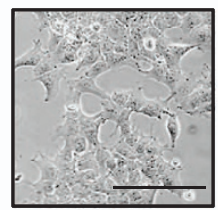

NGF/TRAIL

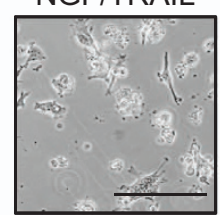

d

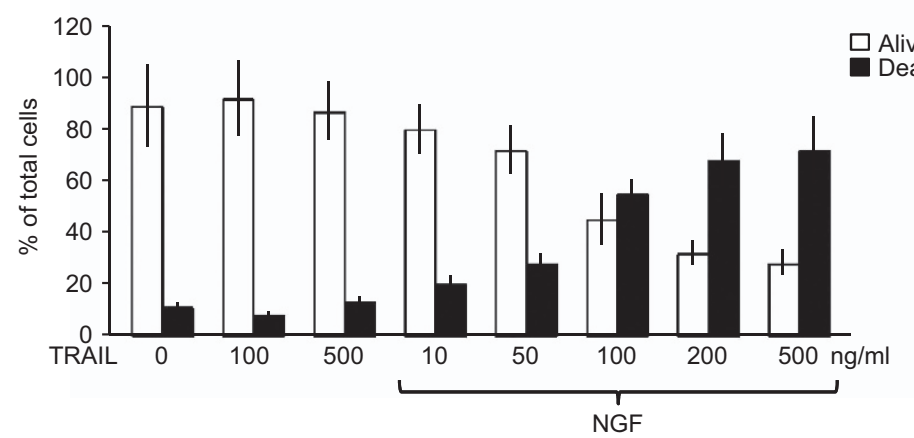

b
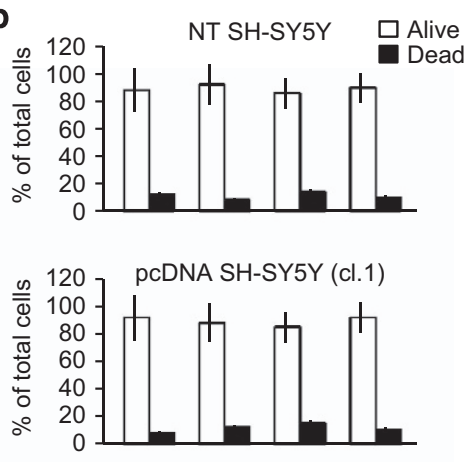

ڤ 120 pcDNA SH-SY5Y (cl.2)
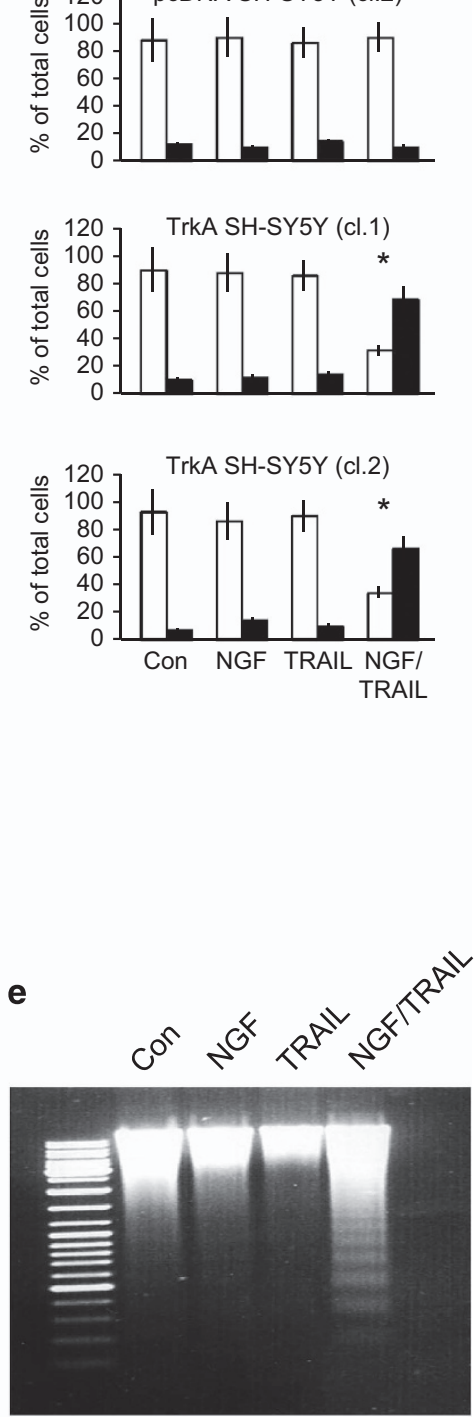

TrkA SH-SY5Y

Figure 1. NGF sensitizes TrkA SH-SY5Y cells to TRAIL-induced apoptosis. (a) Representative phase contrast and fluorescent micrographs $($ bar $=100 \mu \mathrm{M})$ and $(\mathbf{b})$ histograms demonstrating the marked induction of TrkA SH-SY5Y but not NT or pCDNA SH-SY5Y cell death following $16 \mathrm{~h}$ of incubation with NGF $(100 \mathrm{ng} / \mathrm{ml})$ plus TRAIL $(200 \mathrm{ng} / \mathrm{ml})$, compared with the lack of cell death in all three cell lines following overnight $(16 \mathrm{~h})$ incubation with either NGF $(100 \mathrm{ng} / \mathrm{ml})$ or TRAIL $(200 \mathrm{ng} / \mathrm{ml})$ alone. Results are displayed as the mean percentage (\%) of alive (white) and dead (black) cells ( \pm S.D.) in three independent experiments each performed in duplicate (*statistical significance). (c) Representative phase contrast micrographs demonstrating the effect of NGF plus TRAIL on the morphology of surviving TrkA SH-SY5Y cells. (d) Histogram demonstrating dose-dependent induction of TrkA SH-SY5Y cell death by TRAIL (10-500 ng/ml) in the presence but not absence of NGF $(100 \mathrm{ng} / \mathrm{m})$. Results are displayed as the mean percentage (\%) ( \pm S.D.) of alive (white) and dead (black) cells in three independent experiments each performed in duplicate. (e) Representative ethidium bromide stained agarose gel demonstrating laddering of DNA purified from TrkA SH-SY5Y cells treated for $16 \mathrm{~h}$ with NGF $(100 \mathrm{ng} / \mathrm{ml})$ plus TRAlL $(200 \mathrm{ng} / \mathrm{ml})$ but not from TrkA SH-SY5Y cells treated with either NGF $(100 \mathrm{ng} / \mathrm{ml})$ or TRAIL $(200 \mathrm{ng} / \mathrm{ml})$ alone. 
a

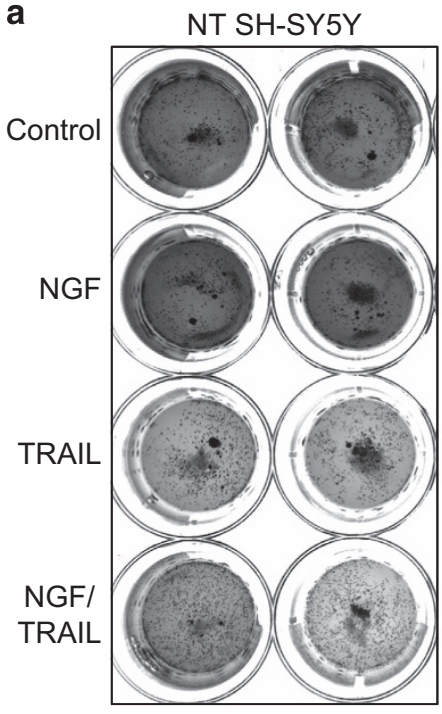

PCDNA SH-SY5Y

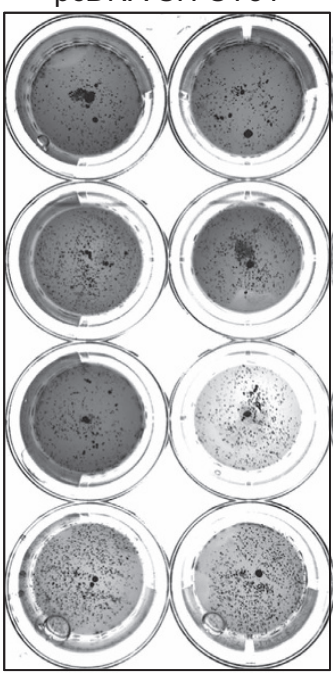

TrkA SH-SY5Y

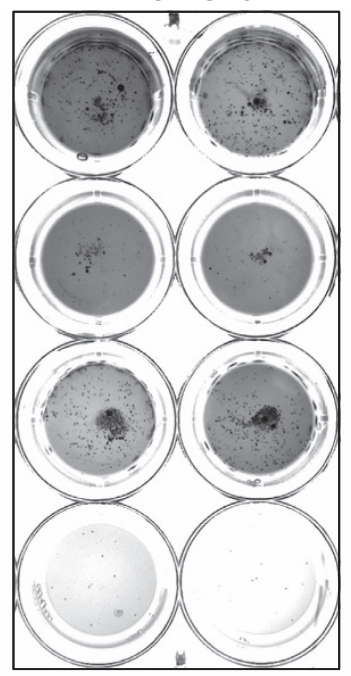

b

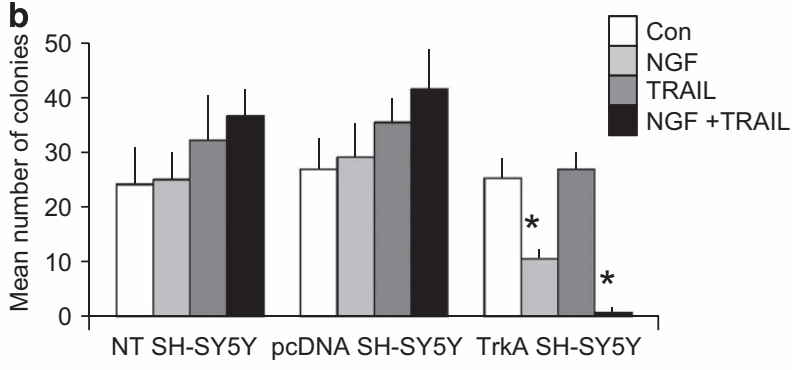

C

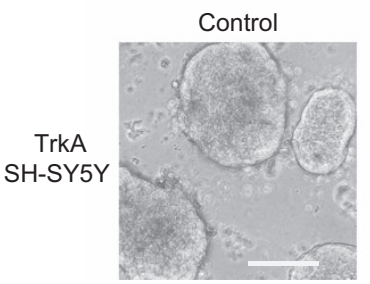

NGF

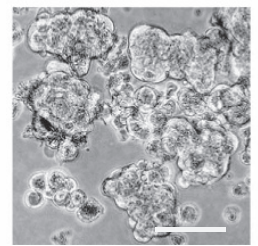

NGF/TRAIL
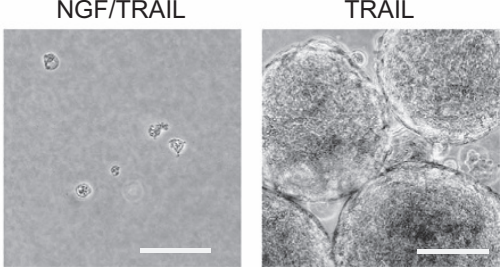

Figure 2. NGF plus TRAIL abrogates the tumourigenic activity of TrkA SH-SY5Y cells in vitro. (a) Representative photograph and (b) histogram demonstrating significant inhibition of TrkA SH-SY5Y but not NT SH-SY5Y or pCDNA SH-SY5Y tumourigenic activity in vitro by NGF (100 ng) alone or in combination with TRAIL (200 ng). Results are displayed as the mean ( \pm S.D.) number of tumours in $10 \times 10$ magnification fields in triplicate experiments each performed in duplicate (*statistical significance). (c) Representative phase contrast micrographs demonstrating tumour spheroid appearance of TrkA SH-SY5Y cells in vitro in the absence (control) or presence of NGF (100 ng/ml), TRAlL (200 ng/ml) plus NGF $(100 \mathrm{ng} / \mathrm{ml})$ or TRAIL $(200 \mathrm{ng} / \mathrm{ml})$ alone.

$(P<0.0001$, d.f. $=10)$ and $15 \pm 23 \%(P=0.0005$, d.f. $=10)$, respectively (Figure 4e). The TrkA tyrosine kinase inhibitors CEP-701, ${ }^{41}$ Gö6976 ${ }^{42}$ and GW441756 ${ }^{43}$ also significantly inhibited TRAILinduced apoptosis of NGF-sensitized TrkA SH-SY5Y cells from a mean ( \pm S.D.) of $73.2 \pm 17 \%$ in controls to $17 \pm 14.5 \%(P<0.0001$, d.f. $=10), \quad 8 \pm 13.3 \% \quad(P<0.0001, \quad$ d.f. $=10) \quad$ and $9.8 \pm 10 \%$ $(P<0.0001$, d.f. $=10)$, respectively (Figure $4 \mathrm{~d}$, phase contrast GW441756 only; and Figure 4e).

Transient $\mathrm{BCl}-\mathrm{xL}$ overexpression (Figure $5 \mathrm{a}$ ) significantly reduced TRAIL-induced apoptosis in NGF-sensitized TrkA SH-SY5Y cells from a mean ( \pm S.D.) of $68.5 \pm 13$ to $25.1 \pm 15 \% \quad(P<0.0003$, d.f. =10; Figure 5b). These data confirm that TRAlL-induced apoptosis of NGF-sensitized TrkA SH-SY5Y cells is dependent upon TrkA activity, is caspase dependent and is mediated through the intrinsic mitochondrial pathway.

The TRAIL-resistant SH-SY5Y phenotype is CFLIP dependent NT SH-SY5Y, PCDNA SH-SY5Y and TrkA SH-SY5Y cells all exhibited similar constitutive high-level cFLIP mRNA and protein expression
(Figures $3 a$ and b). The small interfering RNA (siRNA) cFLIP knockdown (Figure 5c) sensitized TrkA SH-SY5Y cells to TRAILinduced apoptosis in the absence of NGF, resulting in a mean ( \pm S.D.) of $46 \pm 16.2 \%$ death $(P<0.0001$, d.f. $=10$, compared with siRNA-transfected controls; Figure 5d). Transient cFLIP overexpression (Figure 5e) significantly reduced TRAIL-induced apoptosis in NGF-sensitized TrkA SH-SY5Y cells from a mean ( \pm S.D.) of $69 \pm 11.6 \%$ to $36.4 \pm 12.6 \%(P=0.0009$, d.f. $=10$; Figure $5 f)$. These data identify CFLIP as a major mediator of the TRAIL-resistant SH-SY5Y phenotype and regulator of TRAIL-induced apoptosis in NGF-sensitized TrkA SH-SY5Y cells.

NGF induces TrkA-cFLIP binding

NGF $(100 \mathrm{ng} / \mathrm{ml}$ for $1-6 \mathrm{~h})$ did not reduce cFLIP mRNA or protein expression in TrkA SH-SY5Y cells nor induce cFLIP degradation (Figure 4a), suggesting an alternative mechanism for sensitization to TRAIL-induced apoptosis. NGF (100 ng for 1 and $6 \mathrm{~h}$ ), however, induced a binding interaction between TrkA and endogenous CFLIP (Figure 6a) and also between TrkA and 
a

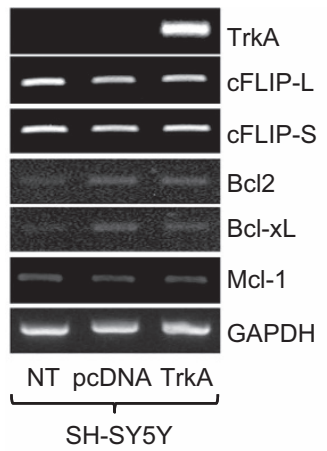

b

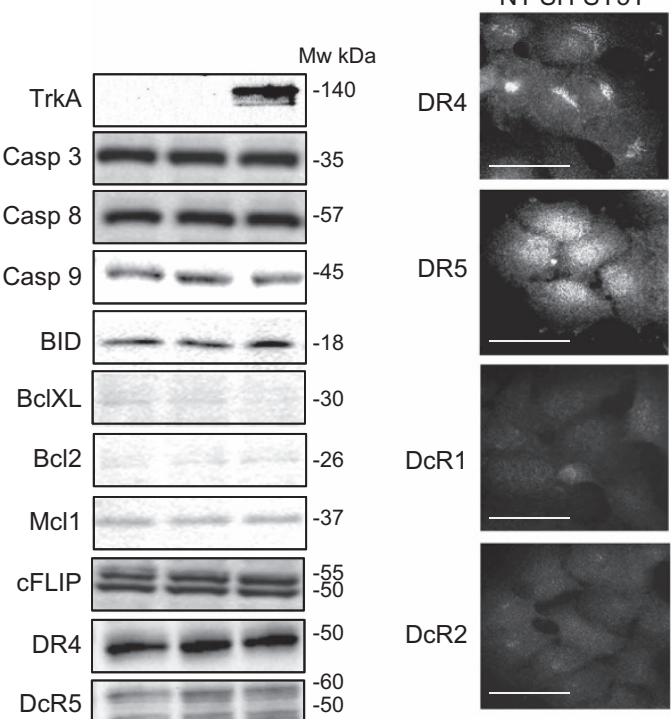

DcR

$\mathrm{DcR}$

$\alpha-$ tub

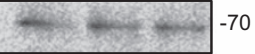

R2 -42

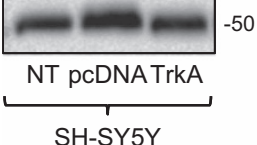

C

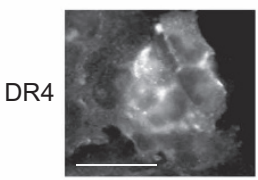

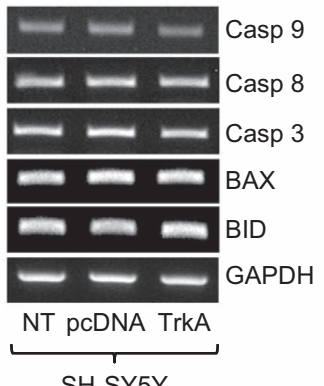

SH-SY5Y

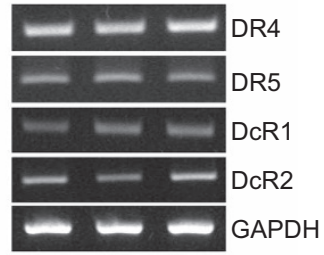

NT pcDNA TrkA

SH-SY5Y
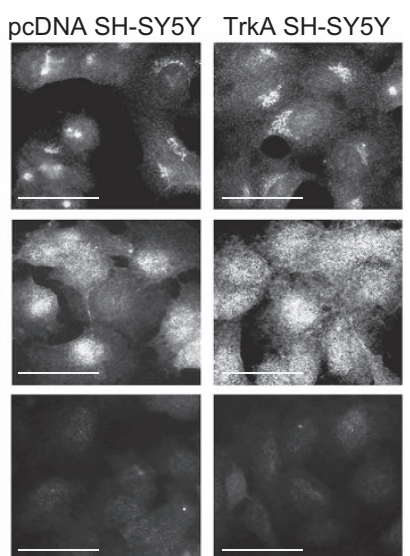

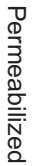
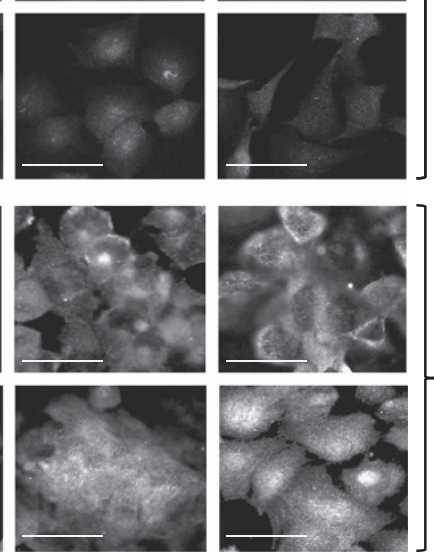

Figure 3. SH-SY5Y cells express all of the major components required for TRAIL-induced apoptosis. (a) Ethidium bromide-stained agarose gels and (b) western blots demonstrating similar RT-PCR product and protein levels for all of the major components involved in TRAIL-induced apoptosis in NT-SH-SY5Y, PCDNA SH-SY5Y and TrkA SH-SY5Y cells. (c) Representative immunofluorescent micrographs demonstrating close similarity in the expression of functional DR4 and DR5 and DcR1 and DcR2 TRAIL receptors in permeabilized cells and similar levels of cell surface DR4 and DR5 immunoreactivity in nonpermeabilized NT-SH-SY5Y, pCDNA SH-SY5Y and TrkA SH-SY5Y cells (bar $=50 \mu \mathrm{M})$.

exogenous FLAG-tagged cFLIP transiently overexpressed in TrkA SH-SY5Y cells (Figure 6b). The TrkA tyrosine kinase inhibitor CEP-701 $(100 \mathrm{nM})$ reduced the binding interaction between TrkA and FLAG-tagged cFLIP detected following $6 \mathrm{~h}$ of incubation with NGF, consistent with a requirement for TrkA tyrosine kinase activity (Figure 6b).

NGF reduces cFLIP recruitment to activated TRAIL death receptors in TrkA SH-SY5Y cells

The possibility that NGF sensitization of TrkA SH-SY5Y cells to TRAIL-induced death results from CFLIP sequestration was confirmed by comparing cFLIP and caspase- 8 levels associated with TRAIL-ligated DR4 death receptor complexes purified from TrkA SH-SY5Y cells preincubated for $6 \mathrm{~h}$ in the presence or absence of NGF $(100 \mathrm{ng} / \mathrm{ml})$ before $1 \mathrm{~h}$ of treatment with biotinylated-TRAIL $(500 \mathrm{ng} / \mathrm{ml})$. Ligand-affinity purified, TRAILligated, DR4-positive death receptor complexes from TrkA SH-SY5Y cells that had been pretreated for $6 \mathrm{~h}$ with NGF $(100 \mathrm{ng} / \mathrm{ml})$ before being treated for $1 \mathrm{~h}$ with biotinylated-TRAIL $(500 \mathrm{ng} / \mathrm{ml})$ contained lower levels of cFLIP, higher levels of caspase-8 and similar levels of DR4 when compared with complexes purified from TrkA SH-SY5Y cells treated with biotinylated-TRAIL $(500 \mathrm{ng} / \mathrm{ml})$, confirming that NGF reduces cFLIP recruitment and increases caspase- 8 recruitment to TRAILactivated death receptors in TrkA SH-SY5Y cells. Similar complexes 
a

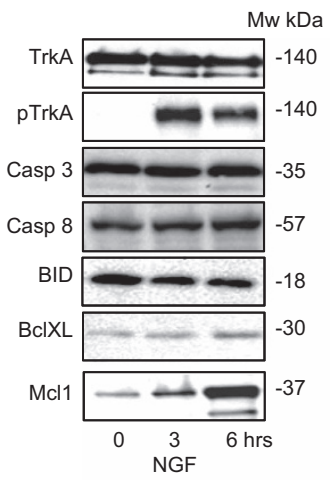

C
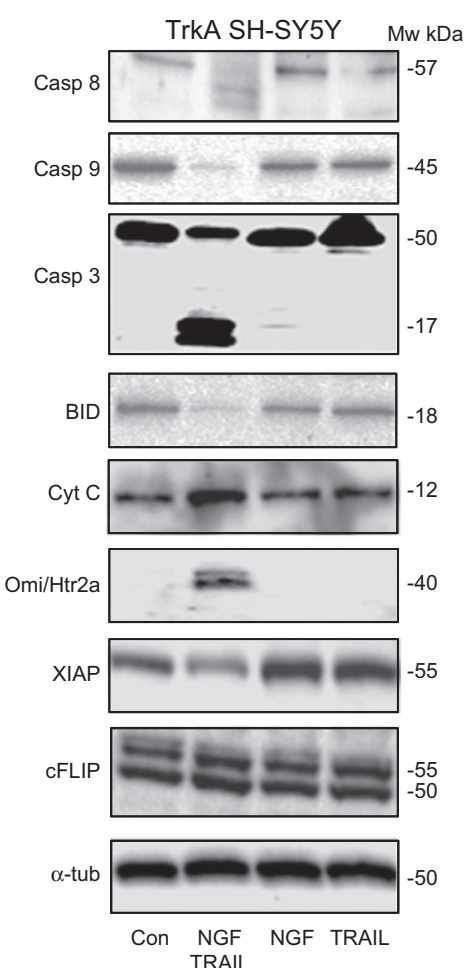

b

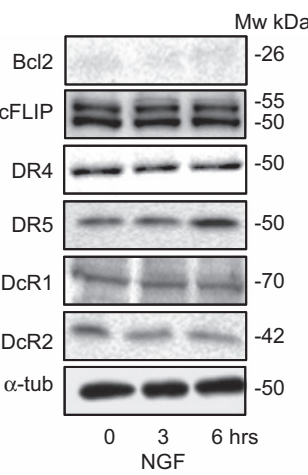

d
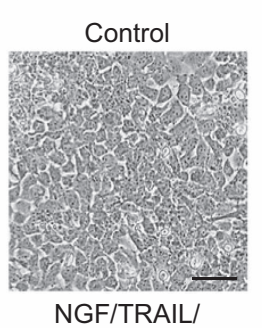

z-VAD-fmk
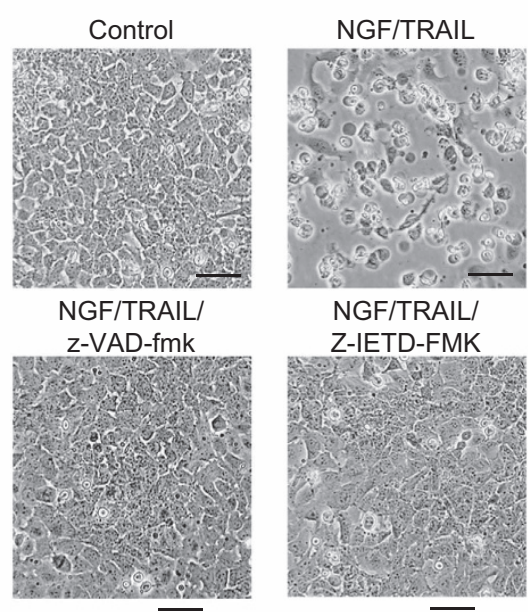

NGF/TRAIL/

Z-IETD-FMK
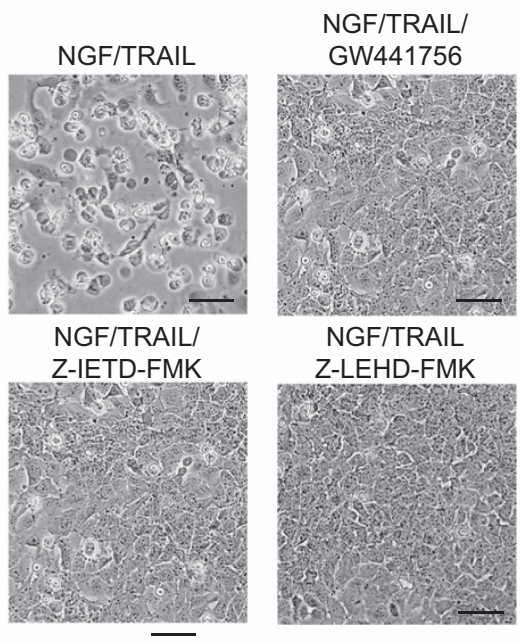

NGF/TRAIL

Z-LEHD-FMK

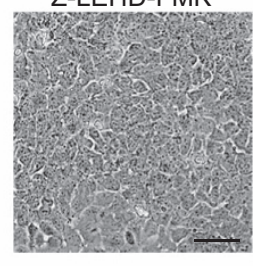

e

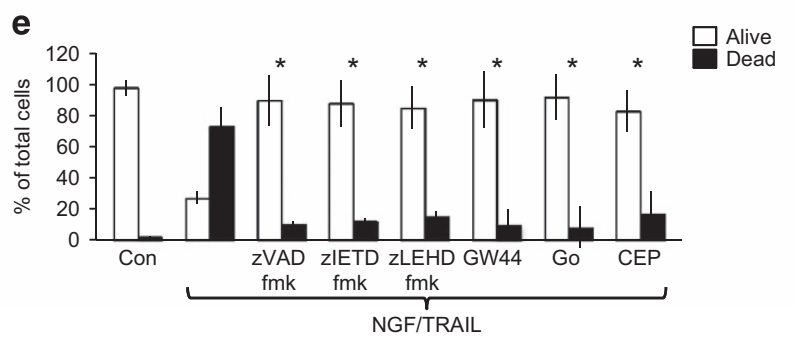

Figure 4. NGF sensitizes TrkA SH-SY5Y cells to TRAIL-induced caspase-dependent type II apoptosis and regulates Mcl-1 but not FLIP expression. (a) Western blots demonstrating NGF stimulation of Mcl-1, Bcl-xL and DR5 protein expression, and the maintenance of TrkA tyrosine phosphorylation in TrkA SH-SY5Y cells over a 1 to $6 \mathrm{~h}$ time course. (b) Agarose gels demonstrating NGF stimulation of Mcl1 and Bcl-xL but not Bcl-2 mRNA expression in TrkA SH-SY5Y cells over a 1-6 h time course. (c) Representative western blots demonstrating changes in cytoplasmic caspase-8, caspase-9, caspase-3, BID, cytochrome C, OMI/Htr2a and XIAP but not in cFLIP or $a$-tubulin in TrkA SH-SY5Y cells treated with a combination of NGF $(100 \mathrm{ng} / \mathrm{ml})$ plus TRAIL $(200 \mathrm{ng} / \mathrm{ml})$ but not with NGF $(100 \mathrm{ng} / \mathrm{ml})$ or TRAIL $(200 \mathrm{ng} / \mathrm{ml})$ alone. (d) Representative phase contrast micrographs (bar $=100 \mu \mathrm{M}$ ) and $(\mathbf{e})$ histogram demonstrating the inhibition of TRAIL-induced apoptosis by z-VAD-fmk, z-IETDfmk, z-LEHD-fmk caspase inhibitors and the TrkA kinase inhibitors CEP-701 (CEP), Gö6976 (Go) and GW441756 (GW) (histogram only). Results are displayed as the mean percentage (\%) ( \pm S.D.) alive (white) or dead (black) cells in three experiments, each performed in duplicate (*statistical significance).

were not purified from untreated TrkA SH-SY5Y cells or TrkA SH-SY5Y cells treated with NGF (100 ng/ml) alone (Figure 6c).

NGF sensitization of TrkA SH-SY5Y cells to TRAlL-induced apoptosis is temporary and eventually inhibited by NF- $K \mathrm{~B}$ and $\mathrm{Mcl}-1$

In preincubation studies, NGF sensitization of TrkA SH-SY5Y cells to TRAIL-induced apoptosis was time dependent and was detected following preincubation with NGF for $1 \mathrm{~h}$ but not $6 \mathrm{~h}$ (Figure 7a). This loss of sensitivity to TRAIL-induced apoptosis following $6 \mathrm{~h}$ of preincubation with NGF did not associate with loss of TrkA Y674/675 phosphorylation (Figure 4a), considered to be an index of TrkA tyrosine kinase activity, ${ }^{44}$ nor with a reduction in the NGF-induced binding interaction between TrkA and FLAGtagged CFLIP (Figure 6b). It did associate, however, with a marked increase in the expression of the mitochondrial apoptosis inhibitor $\mathrm{Mcl}-1,{ }^{45}$ and to a lesser extent $\mathrm{Bcl}-\mathrm{xL}$ but not $\mathrm{Bcl}-2$ (Figure $4 \mathrm{a}$ ). Furthermore, NGF also stimulated the expression of functional DR4 and DR5 but not decoy DcR1 or DcR2 TRAIL receptors, caspase-3, caspase-8, caspase-9, BID or BAX (Bcl-2-associated X protein) (Figures $4 a$ and $b, B A X$ not shown). 
a

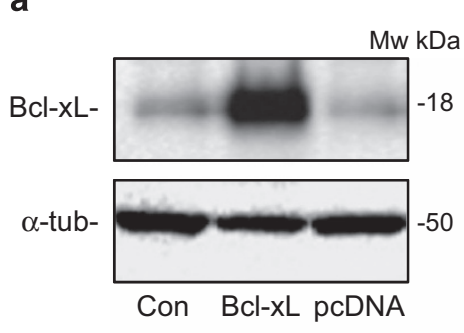

C

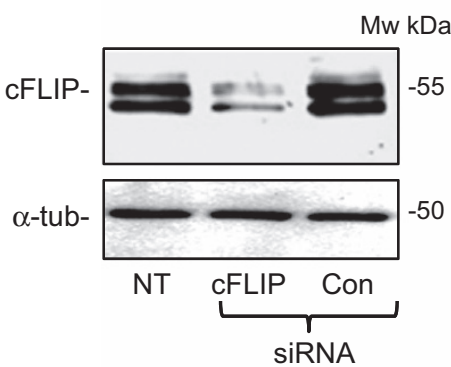

e

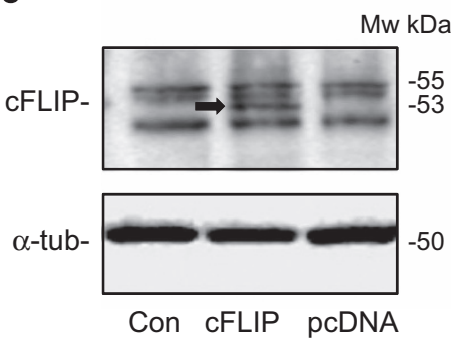

b

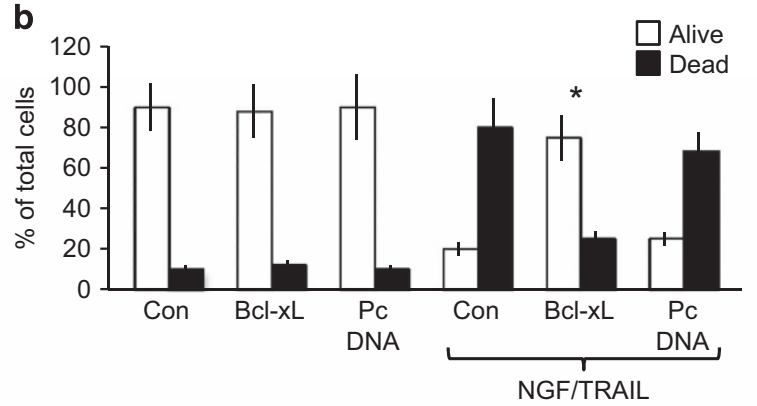

d

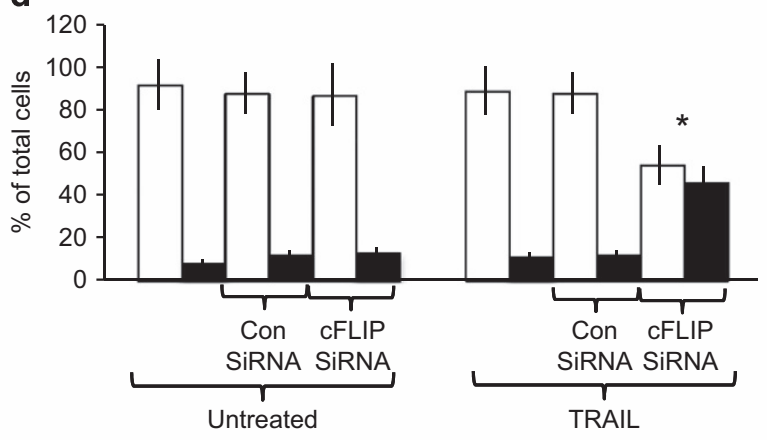

$\mathbf{f}$

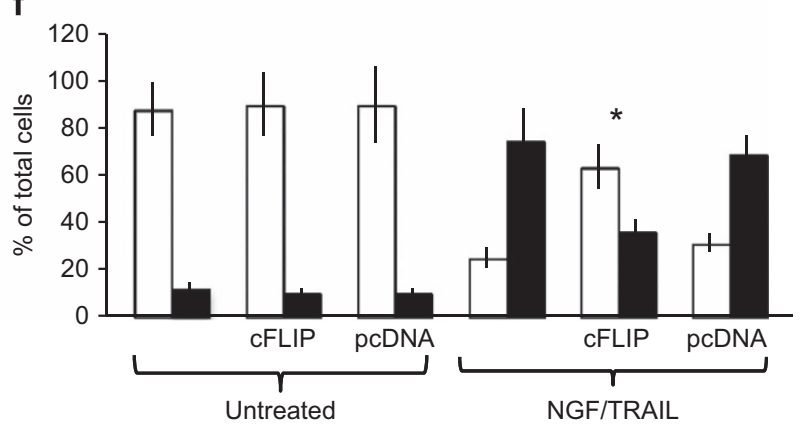

Figure 5. BCl-xL and CFLIP expression block TRAIL-induced apoptosis in NGF-sensitized TrkA SH-SY5Y cells and cFLIP is responsible for the TRAIL-resistant SH-SY5Y phenotype. (a) Western blot demonstrating transient Bcl-xL overexpression in TrkA SH-SY5Y cells transiently transfected with a mammalian pcDNA3.1 Bcl-xL expression vector but not with empty pcDNA3.1 vector. (b) Histogram demonstrating significant $(*)$ inhibition of TRAIL-induced apoptosis in NGF-treated Bcl-xL-transduced but not empty vector-transfected TrkA SH-SY5Y cells in response to NGF (100 ng/ml) plus TRAIL ( $200 \mathrm{ng} / \mathrm{ml})$. (c) Representative western blots demonstrating cFLIP-specific siRNA but not control siRNA knockdown of cFLIP but not $a$-tubulin in TrkA SH-SY5Y cells. (d) Histogram demonstrating a significant ${ }^{*}$ ) increase in apoptosis of TrkA SH-SY5Y cells exhibiting siRNA cFLIP knockdown (cFLIP siRNA) but not in cells transiently transfected with control siRNA duplexes (Con SiRNA) in the presence but not absence of TRAIL and in the absence of NGF. (e) Representative western blot demonstrating transient overexpression of FLAG-tagged cFLIP in TrkA SH-SY5Y cells but not in cells transfected with empty pcDNA expression vector. (f) Histogram demonstrating a significant $\left(^{*}\right)$ reduction in TrkA SH-SY5Y apoptosis induced by NGF $(100 \mathrm{ng} / \mathrm{ml})$ plus TRAlL $(200 \mathrm{ng} / \mathrm{ml})$ in TrkA SH-SY5Y cells that transiently overexpress exogenous FLAG-tagged cFLIP compared with empty expression vector-transfected counterparts. Histogram results are displayed as the mean percentage (\%) ( \pm S.D.) alive (white) or dead (black) cells in three experiments, each performed in duplicate $\left({ }^{*}\right.$ statistical significance).

The siRNA Mcl-1 knockdown in TrkA SH-SY5Y cells reduced constitutive $\mathrm{Mcl}-1$ expression and inhibited NGF stimulation of $\mathrm{Mcl}-1$ expression (Figure 7a). Mcl-1 knockdown also prevented loss of sensitivity to TRAIL-induced apoptosis, following $6 \mathrm{~h}$ of preincubation with NGF (Figures 7b and c). Mcl-1 knockdown, however, did not sensitize NT SH-SY5Y, pcDNA SH-SY5Y or TrkA SH-SY5Y cells to TRAIL-induced apoptosis in the absence of NGF (data not displayed), confirming that $\mathrm{Mcl}-1$ was not directly responsible for the TRAIL-resistant SH-SY5Y phenotype despite being largely responsible for the loss of sensitivity to TRAIL, observed following $6 \mathrm{~h}$ of preincubation with NGF.

The transcription factor NF- $\mathrm{KB}$ regulates $\mathrm{Mcl}-1$ expression and is activated by NGF in TrkA SH-SY5Y cells. ${ }^{46-48} \mathrm{NF}-\kappa \mathrm{B}$ involvement in NGF-stimulated Mcl-1 expression and loss of sensitivity to TRAIL following $6 \mathrm{~h}$ of NGF preincubation was confirmed by transient expression of dominant-negative NF- $K B(\mathrm{dn}-\mathrm{NF}-\kappa \mathrm{B})$ and also by incubation with the NF- $K B$ inhibitor pyrrolidine dithiocarbamate (PDTC). ${ }^{49,50}$ Both dn-NF- $K B$ and PDTC reduced NGF stimulation of Mcl-1 expression in TrkA SH-SY5Y cells (Figure 7a) and prevented loss of sensitivity to TRAIL-induced apoptosis in TrkA SH-SY5Y cells, following $6 \mathrm{~h}$ of NGF preincubation (Figures $7 \mathrm{~b}$ and $\mathrm{c}$ ).

\section{DISCUSSION}

In the present study, we show that NGF sensitizes TrkA-expressing SH-SY5Y cells to TRAIL-induced apoptosis, unveiling a novel proapoptotic immunological dimension to NGF interaction with the TrkA receptor in transformed human neuroblasts. This mechanism 


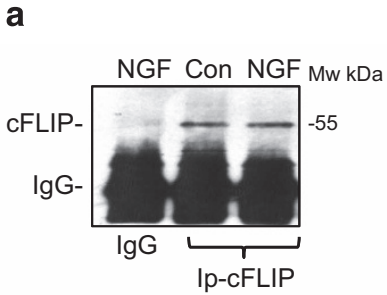

b

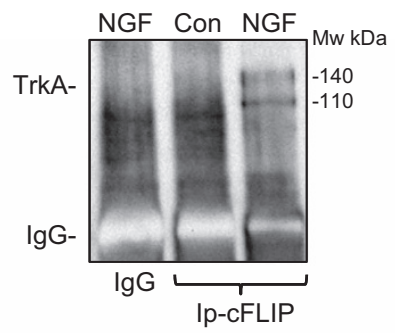

Co-immunoprecipitation

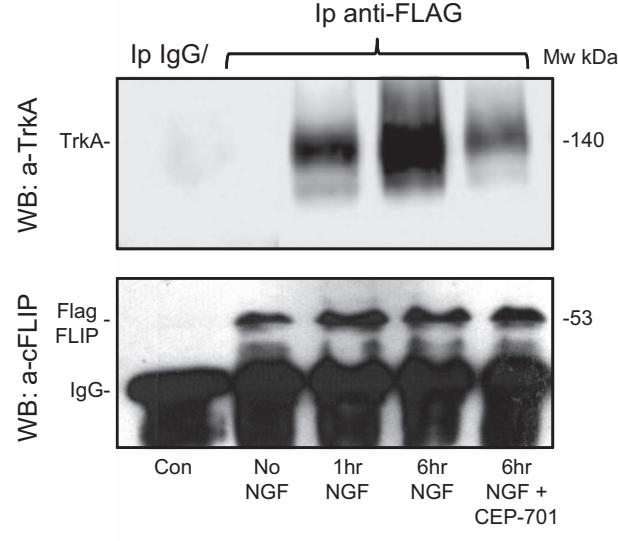

c
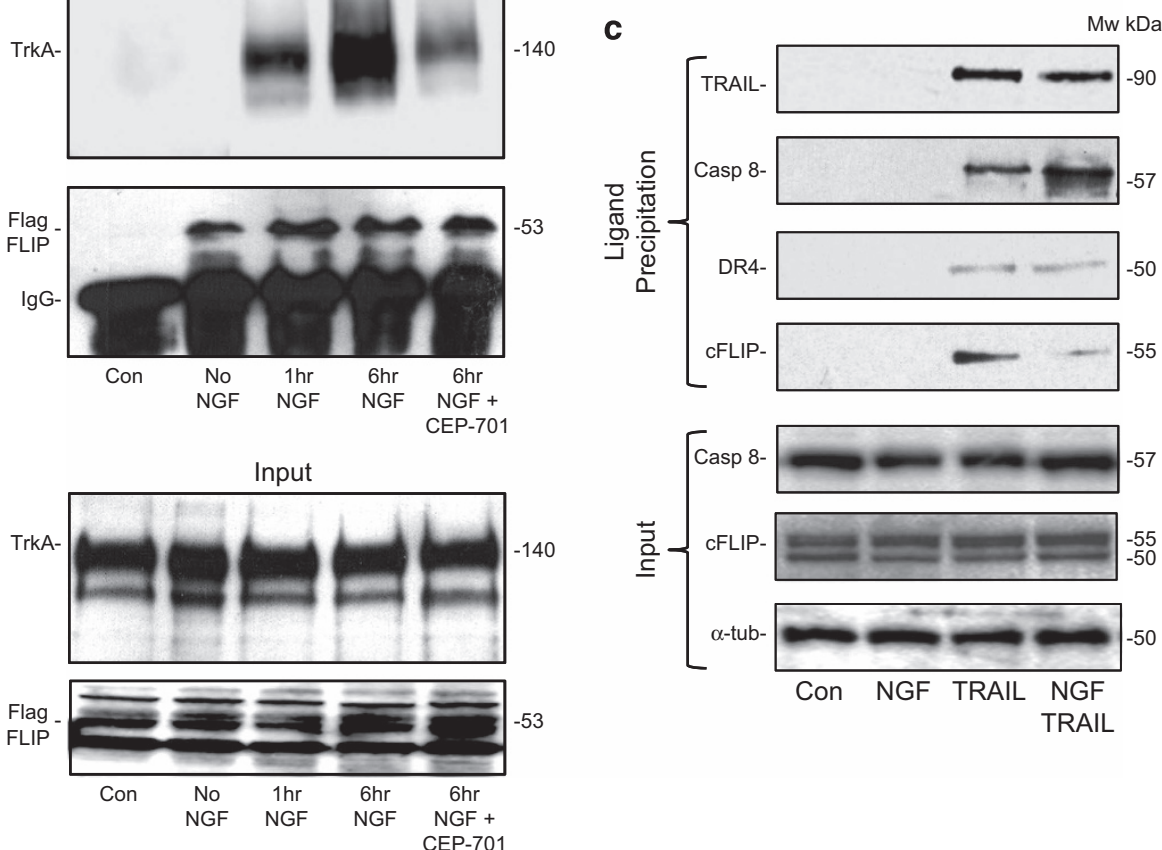

$-53$

Figure 6. NGF induces TrkA/cFLIP binding and reduces the level of cFLIP at death receptors. (a) Representative co-immunoprecipitation western blots demonstrating endogenous CFLIP pull-down of TrkA in immunoprecipitates from total cell extracts (1 mg) of NGF-treated $(100 \mathrm{ng} / \mathrm{ml}$ for $6 \mathrm{~h}$ ) but not untreated TrkA SH-SY5Y cells. (b) Representative co-immunoprecipitation western blots demonstrating exogenous FLAG-tagged cFLIP pull-down of TrkA by immunoprecipitates in whole cell extracts $(300 \mu \mathrm{g})$ of NGF-treated $(100 \mathrm{ng} / \mathrm{ml}$ for $1 \mathrm{and} 6 \mathrm{~h})$ but not untreated TrkA SH-SY5Y cells transiently transfected with a FLAG-tagged cFLIP expression vector. Note the reduced levels of TrkA pulled down by exogenous FLAG-tagged cFLIP in TrkA SH-SY5Y cells co-treated with CEP-701 (100 nM) and NGF for 6 h. Input levels of TrkA and cFLIP are also provided (Input). (c) Representative western blots demonstrating reduced levels of cFLIP and increased levels of caspase-8 in TRAILactivated DR4-positive death receptor complexes purified from TrkA SH-SY5Y cells preincubated for $6 \mathrm{~h}$ with NGF (100 ng/ml) and then treated for $1 \mathrm{~h}$ with biotinylated-TRAIL ( $500 \mathrm{ng} / \mathrm{ml}$ ) (NGF TRAIL) as compared with TrkA SH-SY5Y cells preincubated for $6 \mathrm{~h}$ in the absence of NGF then treated for $1 \mathrm{~h}$ with biotinylated-TRAIL ( $500 \mathrm{ng} / \mathrm{ml}$ ) (TRAIL) and TrkA-SH-SY5Y cells treated for $6 \mathrm{~h}$ with NGF (100 ng/ml) alone (NGF), and untreated TrkA SH-SY5Y cells (Con). Input levels of caspase-8, cFLIP and $a$-tubulin are provided (Input).

depends upon TrkA expression, TrkA activation, caspase and BID cleavage and results in type II apoptosis through the intrinsic mitochondrial pathway. We identify cFLIP as the major mediator of the TRAIL-resistant SH-SY5Y phenotype and provide evidence that NGF sensitization to TRAIL-induced apoptosis results from cFLIP sequestration by NGF-activated TrkA. This reduces CFLIP and increases caspase-8 recruitment to TRAIL-activated death receptors, resulting in the cleavage of caspase- 8 and BID, in turn leading to OMM permeabilization and type II cell apoptosis through the intrinsic mitochondrial pathway. We identify NF- $\kappa \mathrm{B}$ and $\mathrm{Mcl}-1$ as endogenous inhibitors and $\mathrm{NF}-\mathrm{KB}$ and $\mathrm{Mcl}-1$ inhibitors as exogenous optimizers of this novel NGF/TrkA-mediated TRAIL sensitization response.

The TRAIL-resistant SH-SY5Y phenotype could not be explained by the absence of any single component of the TRAIL-induced apoptotic pathway and, in contrast to some reports, ${ }^{19,20,27}$ our SH-SY5Y cell lines exhibited constitutive functional TRAIL receptors and caspase- 8 expression. Furthermore, the relatively low level of decoy (DcR1 and DcR2) relative to functional (DR4 and DR5) TRAIL receptors expression observed suggests that the TRAIL-resistant SH-SY5Y phenotype was not the result of an antiapoptotic equilibrium between functional and decoy TRAIL receptors. Indirect IF and ligand affinity TRAIL receptor purification confirmed that functional TRAIL receptors were expressed at the cell surface, indicating that differential localization of functional and decoy TRAIL receptors was unlikely to be responsible for the TRAIL-resistant phenotype, as reported previously. ${ }^{51} \mathrm{SH}-\mathrm{SY} 5 \mathrm{Y}$ cell lines also exhibited low-level expression of the $\mathrm{BCl}-2$ family proteins, $\mathrm{BCl}-2, \mathrm{BCl}-\mathrm{xL}$ and $\mathrm{MCl}-1$, suggesting that TRAIL resistance was unlikely to depend upon an anti-apoptotic equilibrium between $\mathrm{BCl}-2$ and $\mathrm{BH} 3$-only family proteins.

We identify cFLIP as the major mediator of the TRAIL-resistant SH-SY5Y phenotype, based upon the observations that: TRAIL-resistant cell lines exhibited high-level expression of 


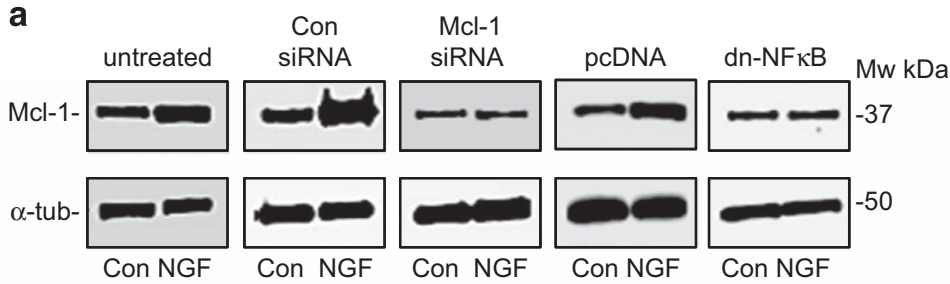

b
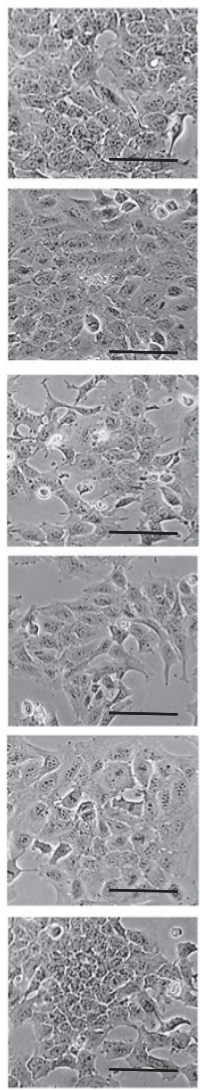

Con
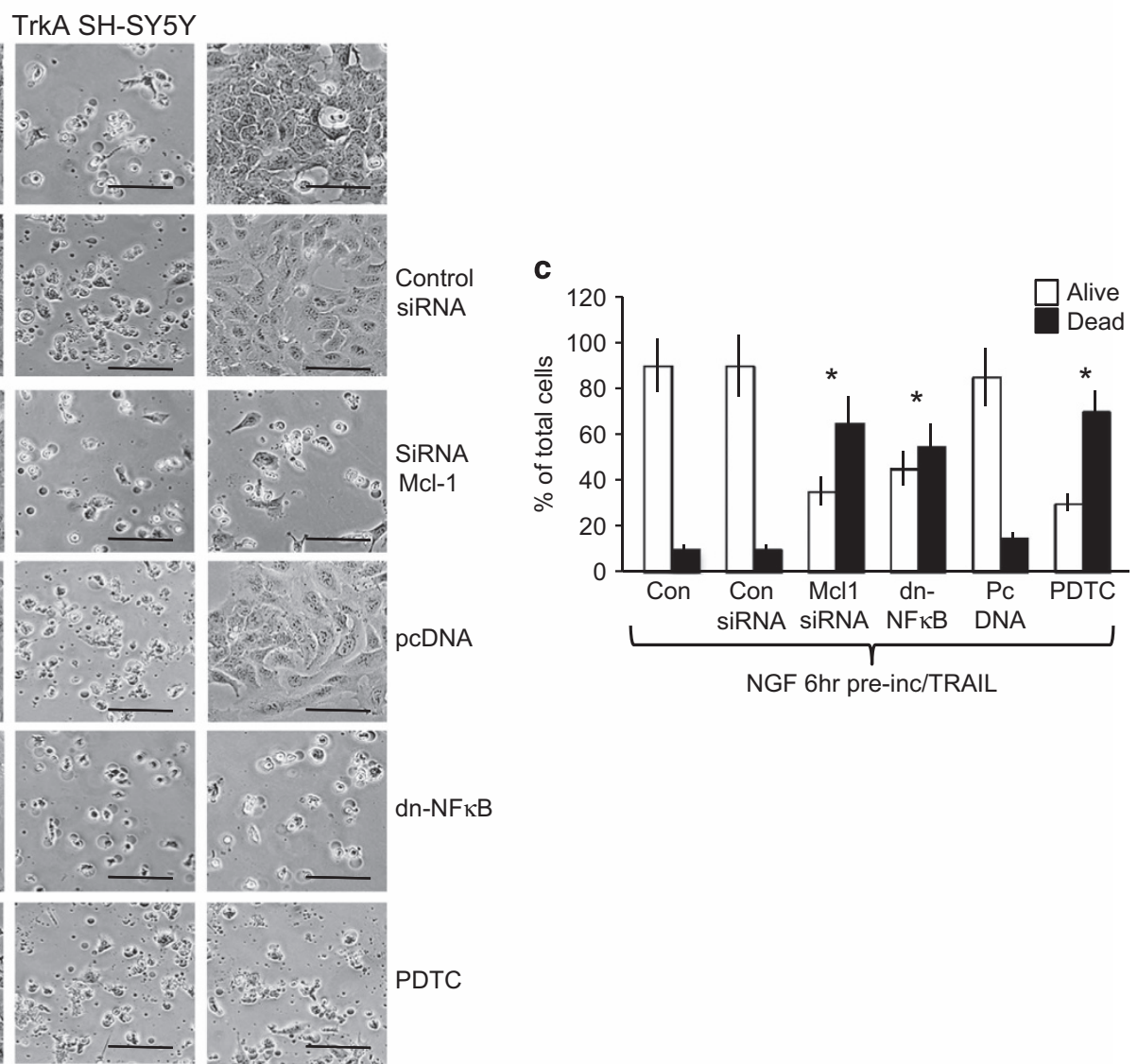

NGF

$1 \mathrm{hr}$ Pre-Inc

TRAIL

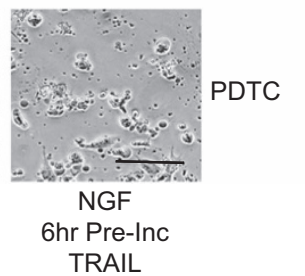

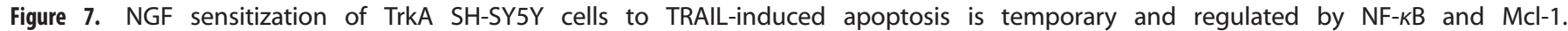
(a) Representative western blots demonstrating NGF (100 ng/ml for $6 \mathrm{~h}$ ) stimulation of constitutive Mcl-1 expression in whole cell extracts $(30 \mu \mathrm{g})$ from untreated, control siRNA-treated and transient empty pcDNA-transfected TrkA SH-SY5Y cells, reduced constitutive Mcl-1 expression and loss of NGF-stimulated Mcl-1 expression in total extracts (30 $\mu \mathrm{g})$ from TrkA SH-SY5Y cells transiently transfected with Mcl-1specific siRNA duplexes and the loss of NGF-stimulated Mcl-1 expression in cells transiently transfected with dn-NF- $k$ B. (b) Representative

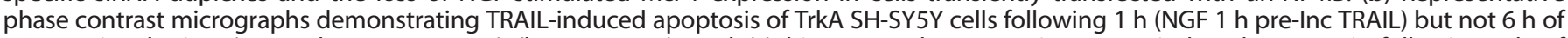
NGF preincubation (NGF $6 \mathrm{~h}$ pre-Inc TRAIL) (bar $=100 \mu \mathrm{M}$ ), and (c) histogram demonstrating TRAIL-induced apoptosis following $6 \mathrm{~h}$ of

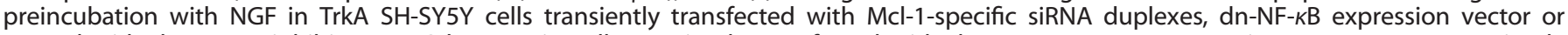
treated with the NF- $K$ B inhibitor PDTC but not in cells transiently transfected with the empty pcDNA expression vector or nontransiently transfected $6 \mathrm{~h}$ NGF pretreated TrkA SH-SY5Y cells (Con). Results are displayed as the mean percentage (\%) ( \pm S.D.) alive (white) or dead (black) of total cells in three independent experiments, each performed in duplicate (*significant difference).

CFLIP (S and L); TRAIL alone did not induce the cleavage of either caspase-8 or BID consistent with a block at the death receptor level; siRNA cFLIP knockdown sensitized TrkA SH-SY5Y cells to TRAIL-induced apoptosis in the absence of NGF; and transient cFLIP overexpression inhibited TRAIL-induced apoptosis in NGF-sensitized TrkA SH-SY5Y cells. However, NGF did not reduce CFLIP expression or induce cFLIP degradation in TrkA SH-SY5Y cells, implicating an alternative sensitization mechanism. A sensitization mechanism based upon CFLIP sequestration was suggested by NGF stimulation of a CEP-701-sensitive binding interaction between NGF-activated TrkA and CFLIP and was confirmed by a reduction in cFLIP and increase in caspase-8 recruitment to TRAIL-activated death receptor complexes. This adds to a recent report that TrkA binds cFLIP during NGF-induced neuritogenesis, ${ }^{52}$ characterizes TrkA as a TRAILactivated TRAIL receptor competitor and supports reports that cFLIP competes with caspase-8 to bind TRAIL-activated TRAIL receptors. ${ }^{53}$ This adds a novel dimension to TrkA function as a regulator of CFLIP involvement in death receptor-mediated apoptosis. The sequestration of CFLIP may also extend to MAPKs 
that also bind CFLIP, ${ }^{54}$ but it remains to be determined whether this may extend to other NT receptors.

NGF sensitization of TrkA SH-SY5Y cells to TRAIL-induced apoptosis was dependent upon TrkA tyrosine kinase activity and was prevented by the TrkA inhibitors CEP-701, ${ }^{41}$ Gö6976, ${ }^{42}$ and GW441756. ${ }^{43}$ Apoptosis was also caspase dependent and prevented by the caspase-3 inhibitor Z-VAD-fmk, ${ }^{55}$ the caspase- 8 inhibitor z-IETD-fmk ${ }^{56}$ and the caspase-9 inhibitor z-LEHD-fmk. ${ }^{57}$ $\mathrm{BCl}-\mathrm{xL}$ overexpression inhibited apoptosis, confirming intrinsic mitochondrial apoptosis pathway involvement that was also supported by the induction of BID cleavage, increased cytosolic levels of the pro-apoptotic mitochondrial proteins cytochrome $C$ and $\mathrm{OMI} / \mathrm{Htr} 2 \mathrm{a}$ and reduced cytosolic levels of the anti-apoptotic protein XIAP, consistent with OMM permeabilization and type II cell apoptotic behaviour. $3,7,58,59$

NGF sensitization of TrkA SH-SY5Y cells to TRAIL-induced apoptosis was temporary and in preincubation studies was detected following preincubation with NGF for $1 \mathrm{~h}$ but not $6 \mathrm{~h}$. This time-dependent loss of sensitivity to TRAIL did not associate with the loss of TrkA tyrosine phosphorylation or a reduction in the binding interaction between TrkA and cFLIP. Furthermore, it was also associated with an increase in the expression of functional (DR4 and DR5) over decoy (DcR1 and DcR2) TRAIL receptors, excluding a potential role for an inhibitory equilibrium between functional and decoy TRAIL receptors. Loss of sensitivity did, however, associate with a marked increase in the expression of the mitochondrial apoptosis inhibitors $\mathrm{Mcl}-1$ and to a lesser extent $\mathrm{BCl}-\mathrm{xL}$. Mcl-1 involvement was confirmed by siRNA knockdown that not only prevented NGF stimulation of $\mathrm{Mcl}-1$ expression but also prevented the loss of TrkA SH-SY5Y cell sensitivity to TRAIL-induced apoptosis following $6 \mathrm{~h}$ of preincubation with NGF. In contrast to its effects upon TRAIL receptor, Mcl-1 and $\mathrm{BCl}-\mathrm{xL}$ expression, NGF did not alter the expression of caspases, $\mathrm{BCl}-2$, BID or BAX.

The transcription factor NF- $K B$ regulates $M c l-1$ expression ${ }^{46,47}$ and is activated by NGF in TrkA SH-SY5Y cells. ${ }^{48} \mathrm{~A}$ role for NF- $K B$ in the regulation of sensitivity to TRAIL was also confirmed using the NF- $K B$ inhibitors dn-NF- $K B$ and PDTC, ${ }^{49,50}$ both of which reduced NGF stimulation of $\mathrm{Mcl}-1$ expression and prevented the loss of TrkA SH-SY5Y cell sensitivity to TRAIL-induced apoptosis following $6 \mathrm{~h}$ of preincubation with NGF. Interestingly, NGF stimulated Mcl-1 and $\mathrm{BCl}-\mathrm{xL}$ but not $\mathrm{Bcl}-2$ expression in TrkA SH-SY5Y cells. Although all three genes have been reported to be NF- $K B$ regulated, ${ }^{46,47,60,61} \mathrm{BCl}-2$ is differentially regulated by the transcription factor CREB (CAMP response element-binding protein) ${ }^{62}$ that is inhibited in SH-SY5Y cells. ${ }^{63}$ We are further investigating this differential regulation of $\mathrm{Mcl}-1, \mathrm{BCl}-\mathrm{xL}$ and $\mathrm{BCl}-2$.

The combination of NGF plus TRAIL inhibited TrkA SH-SY5Y tumourigenicity by $>95 \%$, more than expected, considering that NGF plus TRAIL induced no more than $70 \%$ cell death in a temporary sensitization effect. This can be explained by the differentiation promoting effects of NGF (see this study, and Poluha et $a l^{64}$ and Tacconelli et al. ${ }^{65}$ ) that, despite not inducing apoptosis, caused $50 \%$ inhibition of TrkA SH-SY5Y tumourigenicity in the absence of TRAIL.

In conclusion, we report a novel important pro-apoptotic immunological dimension to the interaction between NGF and the TrkA receptor in sensitizing neuroblastoma cells to TRAILinduced apoptosis. We propose that this mechanism depends upon CFLIP sequestration by activated TrkA receptors and characterizes TrkA as a novel competitive regulator of TRAILinduced apoptosis that competes with death receptor complexes for CFLIP. Our observations may help to explain the association between TrkA expression, better prognosis and spontaneous remission in $\mathrm{NB}^{1}$ and provide a novel potential pro-apoptotic therapeutic strategy, to be developed in the future, for the use of 'painless' forms of $\mathrm{NGF}^{66}$ or alternative TrkA agonists, together with TRAIL and inhibitors of NF-KB and/or Mcl-1 in favourable and unfavourable NBs that express TrkA and exhibit cFLIP-mediated TRAIL resistance. This novel approach may work best as a first-line therapy, as TRAIL receptor activation has recently been reported to promote mutated ki-Ras-driven metastatic progression ${ }^{67}$ and ki-Ras mutations are detected in relapsed but not primary NBs. ${ }^{68-70}$

\section{MATERIALS AND METHODS}

NT, pcDNA control-transfected and TrkA-transfected SH-SY5Y NB cell lines have been described previously. ${ }^{65}$ Cells were grown in RPMI, supplemented with appropriate antibiotics (Zeocin for stable transfectants, penicillin and streptomycin) and 10\% fetal calf serum. TrkA inhibitors Gö6976 ${ }^{42}$ and GW441756; ${ }^{43}$ the NF- $\kappa$ B inhibitor PDTC; ${ }^{50}$ the cell-permeable caspase-3 inhibitor z-VAD-fmk, caspase-8 inhibitor z-IETD-fmk and caspase-9 inhibitor z-LEHD-fmk; NGF and human recombinant TRAIL were purchased from Sigma-Aldrich (St. Louis, MO, USA). The pan Trk inhibitor, CEP-701, ${ }^{41}$ was kindly supplied by Cephalon Inc. (West Chester, PA, USA). Antibodies against TrkA, $a$-tubulin, cFLIP, caspase-8, caspase-9, BID and $\mathrm{Mcl}-1$ were purchased from Santa Cruz (Santa Cruz, CA, USA). Antibodies against phosphorylated Y674/675 TrkA and Caspase-3 were from Cell Signalling (Danvers, MA, USA). Antibodies against DR4, DR5, DcR1 and DcR2 were from ANASPEC (Seraing, Belgium). Antibodies against $\mathrm{BCl}-2$ and $\mathrm{BCl}-\mathrm{xL}$ were from Abcam (Cambridge, UK). Hybond C-extra nitrocellulose membranes and ECL solutions were purchased from Amersham International (Bedford, UK). RNA-easy RNA purification kits were purchased from Qiagen (Hilden, Germany). Mammalian pcDNA expression vectors for $\mathrm{Bcl}-\mathrm{xL}$ and Flag-tagged CFLIP were kindly provided by Dr. Francesca Zazzeroni (University of L'Aquila, L'Aquila, Italy) and have been described previously. $^{71}$ The $d n-N F-\kappa B$ expression vector has been previously described. $^{49}$

\section{Transient overexpression of $\mathrm{Bcl}-\mathrm{xL}, \mathrm{cFLIP}$ and dn-NF- $\kappa \mathrm{B}$}

$\mathrm{BCl}-\mathrm{xL}$, flag-tagged $\mathrm{cFLIP}$ and dn-NF- $\mathrm{KB}$ were overexpressed in SH-SY5Y cell lines by transient transfection of mammalian expression vectors bearing $\mathrm{Bcl}-\mathrm{xL}$, FLAG-tagged cFLIP ${ }^{71}$ or dn-NF-kB. ${ }^{49}$ Briefly, $0.6 \mu \mathrm{g} / \mathrm{ml}$ of each vector was transfected into subconfluent cell cultures using FUGENE transfection reagent as directed by the manufacturer (Promega, Madison, WI, USA). At $6 \mathrm{~h}$ of transfection, medium was replaced with fresh growth medium (RPMI/10\% FCS/glutamine plus antibiotic) and the cells were left for $48 \mathrm{~h}$, at which time they were utilized for experimentation. Overexpression of $\mathrm{BCl}-\mathrm{xL}$ and Flag-tagged cFLIP was verified by western blotting of total cell extracts $(20 \mu \mathrm{g})$.

\section{SiRNA cFLIP and Mcl-1 knockdown}

The cFLIP and Mcl-1 expression was knocked down in NB cells using a TriFECTa Dicer-Substrate RNAi kit, employing three cFLIP-specific or three Mcl-1-specific Dicer-Substrate siRNA duplexes, as described by the manufacturer (Integrated DNA Technologies, Coralville, IA, USA). Briefly, cells were subjected to $48 \mathrm{~h}$ of transient transfection with either $25 \mathrm{nM}$ negative control siRNA duplex (provided with the kit) or $25 \mathrm{nM}$ of a mix of cFLIP-specific or Mcl-1-specific siRNA duplexes, using INTERFERin in vitro siRNA transfection reagent, as described by the manufacturer (Polyplus Transfection Inc., New York, NY, USA). Sham-transfected controls received transfection reagent alone. The siRNA knockdown of cFLIP and $\mathrm{Mcl}-1$ expression was confirmed by western blot comparison with $a$-tubulin in whole cell extracts $(20 \mu \mathrm{g})$.

Mcl-1 siRNA sets were as follows: 5'-AGCCUAGUAUGUCAAUAAAGCAAAT-3' and 5'-AUUUGCUUUUAUUGACAUACUA GGCUUA-3'; 5'-GGAACAAAUCU GAUAACUAUGCAGG-3' and 5'- CCUGCAUAGUUAUCAGAUUUGUUCCAC-3'; and 5'-CAAGUGCAUAGAUGUGAAUUGGUTT- 3 ' and 5'-AAACCAAUUCA CAUCUAUGCACUUGUU-3'. CFLIP siRNA sets were as follows: 5'-UGAG UUGGAGAAACUAAAUCUGGTT-3' and 5'-AACCAGAUUUAGUUUCUCCAACU CAAC-3'; 5'-CGAAGACCCUUGUGAGCUUCCCUAG-3' and 5'-CUAGGGA AGCUCACAAGGGUCUUGCAG-3'; and 5'-GCCGAGGCAAGAUAAGCAAG GAGAA-3' and 5'-UUCUCCUUGCUUAUCUUGCCUCGGCCC-3'.

Transfection efficiency was confirmed using a HPRT-S1 DS positive control and validated using a negative control duplex (NC1) not present in the human genome, as described by the manufacturer (Integrated DNA Technologies; www.IDTDNA.com). 
Cell extraction, immunoprecipitation and western blotting

Cells were extracted in lysis buffer (PBS containing $0.5 \%$ sodium deoxycholate, $1 \% \mathrm{NP}-40,0.1 \% \mathrm{SDS}, 1 \mathrm{mM}$ sodium orthovanadate, $1 \mathrm{mM}$ PMSF, $1 \mu \mathrm{g} / \mathrm{ml}$ of pepstatin A and aprotinin) and protein concentrations were calculated by Bradford protein concentration assay (Sigma-Aldrich). Cytoplasmic levels of cytochrome $C$ and $\mathrm{Omi} / \mathrm{Htr} 2 \mathrm{a}$ were assessed in the same lysates, following removal of mitochondria. Briefly, cell lysates were centrifuged at $3000 \times g$ for 5 min at $4{ }^{\circ} \mathrm{C}$, supernatants containing cytosol and mitochondria recovered and centrifuged at $15000 \times g$ for $30 \mathrm{~min}$ at $4{ }^{\circ} \mathrm{C}$. The mitochondria-free supernatant was taken and recentrifuged at $15000 \times g$ at $4{ }^{\circ} \mathrm{C}$ to give the mitochondria-free sample for western blotting. Samples were mixed with reducing sodium dodecyl sulphatepolyacrylamide gel electrophoresis (SDS-PAGE) sample buffer and subjected to reducing SDS-PAGE/western blotting. Briefly, proteins separated by reducing SDS-PAGE were transblotted onto Hybond $\mathrm{C}+$ nitrocellulose membranes by electrophoresis (Amersham International) and the membranes subsequently air-dried. Nonspecific protein binding site on membranes were blocked by incubation for $2 \mathrm{~h}$ in $5 \%$ non-fat milk in Tris-buffered saline and Tween-20 (TBS-T) before incubation with primary antibodies, at recommended dilutions, for $2-16 \mathrm{~h}$ at $4{ }^{\circ} \mathrm{C}$. Membranes were then washed in TBS-T, incubated with secondary HRPconjugated antibodies (Jackson ImmunoResearch Laboratories, West Grove, PA, USA) diluted in blocking solution and immunoreactive species detected by chemiluminescence reaction, as directed by the manufacturer (Amersham International).

\section{RNA purification and reverse transcription-PCR (RT-PCR)}

RT reactions were performed on total RNAs $(1 \mu \mathrm{g})$, purified using RNA-easy Plus, as described by the manufacturer (Qiagen) using the Moloney Murine Leukemia virus RT kit as detailed by the manufacturer (LifeTechnologies, Inc., Paisley, UK). RT reactions were subjected to PCR using the following primers: GAP: 5'-AGGTCCACCACTGACAGTT-3' (forward) and 5'-CTGCA CCACCAACTGCTTAG-3' (reverse) (300 bp); TrkA: 5'-AGAAGCTGCAGTGT CATGGG-3' (forward) and 5'-ATTGAGCACGGAGCCATTGA-3' (reverse) (452 bp); DcR1: 5'-GAAGAATTTGGTGCCAATGCCACTG-3' (forward) and 5'-CTCTTGGACTTGGCTGGGAGATGTG-3' (reverse) (612 bp); DcR2: 5'-CCC CCGGCAGGACGAAGTT-3' (forward) and 5'-CTCCTCCGCTGCTGGGGTाTा-3' (reverse) (418 bp); DR4: 5'-ACTTTGGTTGTCCGTTGCTGTTG-3' (forward) and 5'-GGCTITCCATTTGCTGCTCA-3' (reverse) (214 bp); DR5: 5'-CTGAAAGGC ATCTGCTCAGGTG-3' (forward) and 5'-CAGAGTCTGCATTACCTTCTAG-3' (reverse) (347 bp); cFLIPs: 5'-GGACCTTGTGGTTGAGTTGG-3' (forward) and 5'-ATCAGGACAATGGGCATAGG-3' (reverse) (241 bp); cFLIP : 5'-GGCTCCCA GAGTGTGTATGG-3' (forward) and 5'-AGCTTCTCGGTGAACTGTGC-3' (reverse) (249 bp); Bcl-2: 5'-GACTTCGCCGAGATGTCC-3' (forward) and 5'-CAAGCTCCCACCAGGGCCAAAC-3' (reverse) (356 bp); BCl-xL: 5'-GTGA ATTCTGAGGCCAAGGGAAC-3' (forward) and $5^{\prime}$-GAACGGCGGCTGGGATA CTIT TG-3' (reverse) (373 bp); caspase-8: 5'-TCTGGAGCATCTGCTGTCTG-3' (forward) and 5'-CCTGCCTGGTGTCTGAAGTT-3' (reverse) (427 bp); caspase-10: 5'-GGGAACGGACACACAACTCT-3' (forward) and 5'-CTAGCTITTGGCCCTG ACTG-3' (reverse) (293 bp); caspase-3: 5'-TTAATAAAGGTATCCATGGAGAAC ACT-3' (forward) and 5'-TTAGTGATAAAAATAGAGTTCTTTTGTGAG-3' (reverse) (849 bp); BAX: 5'-AAGAAGCTGAGCGAGTGT-3' (forward) and 5'-GGAGGAAG TCCAATGTC-3' (reverse) (256 bp); Mcl-1: 5'-AAGCCAATGGGCAGGTCT-3' (forward) and 5'-TGTCCAGTTTCCGAAGCAT-3' (reverse) (121 bp).

For each primer set, PCRs were performed on reverse transcription reactions serially diluted from 1 to $1: 1000$. Reactions below saturation were compared by densitometric analysis of Jpeg images of ethidium bromide stained gels, using ImageJ64 software. ${ }^{72}$

\section{Analysis of apoptosis and the cell death assay}

TRAlL-induced apoptosis was confirmed by in situ Tunel assay as described by the manufacturer (R\&D Systems, Minneapolis, MN, USA). For DNA ladder analysis, cells were collected by centrifugation at 5000 r.p.m. for 5 min, lysed, incubated at room temperature for $10 \mathrm{~min}$ and then incubated for $5 \mathrm{~min}$ at $65^{\circ} \mathrm{C}$. Samples, cooled to room temperature for $5 \mathrm{~min}$, were mixed with $700 \mu \mathrm{l}$ of chloroform-isoamyl alcohol and centrifuged for $5 \mathrm{~min}$ at 12000 r.p.m. The aquatic (upper) phase was transferred, an equal volume of cold isopropanol was added, mixed gently by inversion and centrifuged for $5 \mathrm{~min}$ at 12000 r.p.m. The supernatant was discarded and pellet air-dried for $30 \mathrm{~min}$. Dried DNA was dissolved in $50 \mu \mathrm{l}$ of distilled water, quantified in a spectrophotometer (NanoDrop 1000, Wilmington, $\mathrm{DE}, \mathrm{USA}$ ) and analysed by $1.5 \%$ agarose gel electrophoresis.
Cell death was routinely assayed using a modification of previously described methods. ${ }^{73,74}$ Briefly, cells were washed once in $\mathrm{Ca}^{2+}$-free PBS, detached with ice-cold PBS containing $1 \mathrm{mM}$ EDTA, transferred to sterile $15 \mathrm{ml}$ tubes, centrifuged for $5 \mathrm{~min}$ at $1000 \times g$ at $4{ }^{\circ} \mathrm{C}$, washed with ice-cold PBS and repelleted by centrifugation at $1000 \times g$ for $5 \mathrm{~min}$ at $4{ }^{\circ} \mathrm{C}$. Cell pellets were resuspended in $25 \mu \mathrm{l}$ of PBS containing $2 \mu \mathrm{l}$ of acridine orange/ethidium bromide solution $(100 \mu \mathrm{g} / \mathrm{ml}$ acridine orange and $100 \mu \mathrm{g} / \mathrm{ml}$ ethidium bromide in PBS) plated onto glass slides and examined immediately under a Zeiss (Carl Zeiss, Oberkochen, Germany) 'Axioplan-2' fluorescence microscope. Representative fields were digitally photographed under identical exposure conditions and the number of dead cells (orange/red nuclei) and live cells (green nuclei) counted. In addition to this assay, phase contrast micrographs of parallel cultures were used to confirm changes in the relative percentage of adherent and suspension (predominantly apoptotic) cells following TRAIL treatment.

\section{Tumour growth in soft agar}

For substrate-independent tumour growth assays, $1 \times 10^{4}$ cells in singlecell suspension (passed through a gauge $\times 18$ syringe needle) were mixed in a $0.3 \%$ solution of agar (BiTech Difco-BD, Milan, Italy) in RPMI containing $5 \%$ FCS at $37{ }^{\circ} \mathrm{C}$, with or without NGF $(100 \mathrm{ng} / \mathrm{ml})$ and/or TRAlL $(200 \mathrm{ng} / \mathrm{ml})$ and layered onto a solid $0.6 \%$ agarose substrate also with and without NGF and/or TRAIL, prepared in the same growth medium. Following top phase agar solidification, complete medium was added and replaced every 2 days. Tumour spheroid growth was monitored over a 14-day period by phase contrast microscopy. Tumour spheroids were counted in 10 random fields at $\times 10$ magnification.

\section{Isolation of TRAIL-activated TRAIL receptor complexes}

TRAIL-ligated death receptor complexes were purified from TrkA SH-SY5Y cells by ligand affinity precipitation, as previously described. ${ }^{75}$ Briefly, biotinylated TRAIL was prepared by incubating TRAIL $(1 \mathrm{mg} / \mathrm{ml})$ with SulfoNHS-LC-Biotin ( $1 \mathrm{mg} / \mathrm{ml}$; Thermo Fisher Scientific, Waltham, MA, USA) for $1 \mathrm{~h}$ on ice. The reaction was stopped by adding $1: 10$ volume of $1 \mathrm{M}$ Tris$\mathrm{HCl}(\mathrm{pH} 7.5)$ and unincorporated biotin removed by buffer exchange into $150 \mathrm{mM} \mathrm{NaCl}, 30 \mathrm{mM}$ HEPES (pH 7.5) using PD-10 columns (Amersham Pharmacia Biotech, Piscataway, NJ, USA). For ligand affinity precipitation, cells $\left(5 \times 10^{6}\right.$ cells per sample) were washed twice in RPMI at $37^{\circ} \mathrm{C}$ and incubated with $1 \mu \mathrm{g} / \mathrm{ml}$ biotinylated TRAIL for $1 \mathrm{~h}$. Death receptor complex formation was stopped by the addition of 15 volumes of ice-cold PBS and cells were then lysed in $4.5 \mathrm{ml}$ of lysis buffer $(30 \mathrm{mM}$ TRIS-HCl (pH 7.5), $150 \mathrm{mM} \mathrm{NaCl,} \mathrm{10 \%} \mathrm{glycerol,} \mathrm{1 \%} \mathrm{Triton} \mathrm{X-100,}$ supplemented with complete protease inhibitor cocktail; Roche Diagnostics, Mannheim, Germany). TRAIL receptor protein complexes were precipitated from lysates by co-incubation with $20 \mu \mathrm{l}$ of Streptavidin beads (Pierce) for $3 \mathrm{~h}$ at $4{ }^{\circ} \mathrm{C}$ with rotation. Ligand affinity precipitates were washed four times in lysis buffer, eluted from beads in reducing SDS-PAGE sample buffer and subjected to SDS-PAGE western blotting.

\section{Statistical analysis}

Data were analysed statistically by Student's $t$-test and statistical significance was associated with probabilities of $\leqslant 0.05$.

\section{ABBREVIATIONS}

NB, neuroblastoma; TNF, tumour necrosis factor; TRAIL, TNF-related apoptotis-inducing ligand; CFLIP, cellular FLICE-like inhibitory protein; NF$\kappa B$, nuclear factor- $k$ binding; dn-NF- $k B$, dominant-negative NF- $k B$; NGF, nerve growth factor; Trk, tropomyosin-related kinase; Mcl-1, myeloid cell leukaemia-1; Bcl-2, B-cell lymphoma 2; Bcl-xL, B-cell lymphoma extra large; $\mathrm{BH} 3$-only, $\mathrm{BCl}-2$ homology domain 3-only; $\mathrm{BID}, \mathrm{BH} 3$ interacting domain death agonist; FADD, Fas-associated protein with death domain; OMM, outer mitochondrial membrane; DcR, decoy receptor; siRNA, small interfering RNA; XIAP, X-linked inhibitor of apoptosis; AIF, apoptosisinducing factor; $\mathrm{BAX}, \mathrm{BCl}$-2-associated $\mathrm{X}$ protein; $\mathrm{PDTC}$, pyrrolidine dithiocarbamate; NT, nontransfected; CREB, CAMP response elementbinding protein; TBS-T, Tris-buffered saline and Tween-20; SDS-PAGE, sodium dodecyl sulphate-polyacrylamide gel electrophoresis; RT-PCR, reverse transcription-PCR; SMAC/DIABLO, second mitochondria-derived activator of caspases. 


\section{ACKNOWLEDGEMENTS}

This work was supported by the Maugeri Foundation.

\section{COMPETING INTERESTS}

The authors declare no conflict of interest.

\section{REFERENCES}

1 Ruggeri P, Farina AR, Cappabianca L, Di lanni N, Ragone M, Merolle S et al. Neurotrophin and neurotrophin receptor involvement in human neuroblastoma. In: Shimada H (ed). Neuroblastoma. InTech: Rijeka, Croatia, 2013.

2 Ashkenazi A. Targeting the extrinsic apoptotic pathway in cancer: lessons learned and future directions. J Clin Invest 2015; 125: 487-489.

3 Xiong S, Mu T, Wang G, Jiang X. Mitochondria-mediated apoptosis in mammals. Protein Cell 2014; 5: 737-749.

4 Carswell EA, Old LJ, Kassel RL, Green S, Fiore N, Williamson B. An endotoxininduced serum factor that causes necrosis of tumors. Proc Natl Acad Sci USA 1975; 72: $3666-3670$

5 Ashkenazi A, Dixit VM. Death receptors: signaling and modulation. Science 1998; 281: 1305-1308.

6 Russo M, Mupo A, Spagnuolo C, Russo GL. Exploring death receptor pathways as selective targets in cancer therapy. Biochem Pharmacol 2010; 80: 674-682.

7 Tait SW, Green DR. Mitochondria and cell death: outer membrane permeabilization and beyond. Nat Rev Mol Cell Biol 2010; 11: 621-632.

8 Cregan SP, Dawson VL, Slack RS. Role of AIF in caspase-dependent and caspaseindependent cell death. Oncogene 2004; 23: 2785-2796.

9 Fulda S, Debatin K-M. Extrinsic versus intrinsic apoptosis pathways in anticancer chemotherapy. Oncogene 2006; 25: 4798-4811.

10 Ashkenazi A, Holland P, Eckhardt SG. Ligand-based targeting of apoptosis in cancer: the potential of recombinant human apoptosis ligand 2/tumor necrosis factor-related apoptosis- inducing ligand (rhApo2L/TRAIL). J Clin Oncol 2008; 26: 3621-3630.

11 Nagane M, Huang HJ, Cavenee WK. The potential of TRAIL for cancer chemotherapy. Apoptosis 2001; 6: 191-197.

12 Hall MA, Cleavland JL. Clearing the TRAIL for cancer therapy. Cancer Cell 2007; 12: 4-6.

13 Van Dijk M, Halpin-McCormick A, Sessler T, Samali A, Szegezdi E. Resistance to TRAIL in non-transformed cells is due to multiple redundant pathways. Cell Death Dis 2013; 4: e702.

14 Martinez-Lostao L, Marzo I, Anel A, Naval J. Targeting the Apo2L/TRAIL system for the therapy of autoimmune diseases and cancer. Biochem Pharmacol 2012; 83: 1475-1483.

15 Safa AR, Pollok KE. Targeting the anti-apoptotic protein c-FLIP for cancer therapy. Cancers 2011; 3: 1639-1671.

16 Trivedi R, Mishra DP. Trailing TRAIL resistance: novel targets for TRAIL sensitization in cancer cells. Front Oncol 2015; 5: 1-20.

17 Fulda S, Meyer E, Debatin K-M. Inhibition of TRAIL-induced apoptosis by Bcl-2 overexpression. Oncogene 2002; 21: 2283-2294.

18 Yang $X$, Thiele CJ. Targeting the tumour necrosis factor-related apoptosisinducing ligand pathway in neuroblastoma. Cancer Lett 2003; 197: 137-143.

19 Miller MA, Karacay B, Zhu X, D'Orisio MS, Sandler AD. Caspase 8L, a novel inhibitory isoform of caspase 8 is associated with undifferentiated neuroblastoma. Apoptosis 2006; 11: 15-24.

20 Hopkins-Donaldson S, Bodmer J-L, Balmas Bourloud K, Brognara CB, Tschopp J, Gross N. Loss of caspase-8 expression in highly malignant human neuroblastoma correlates with resistance to tumor necrosis factor-related apoptosis-inducing ligand-induced apoptosis. Cancer Res 2000; 60: 4315-4319.

21 Goldsmith KC, Hogarty MD. Targeting programmed cell death pathways with experimental therapeutics: opportunities in high-risk neuroblastoma. Cancer Lett 2005; 228: 133-141.

22 Karacay B, Sanlioglu S, Griffith TS, Sandler A, Bonthius DJ. Inhibition of the NF- $k$ B pathway enhances TRAIL-mediated apoptosis in neuroblastoma cells. Cancer Gene Ther 2004; 11: 681-690.

23 Efron PA, Chen MK, lyengar M, Dai W, Nagaram A, Beierle EA. Differential response of neuroblastoma cells to TRAIL is independent of PI3K/Akt. J Ped Surg 2006; 41: 1072-1080.

24 Poulaki V, Mitsiades N, Romero ME, Tsokos M. Fas-mediated apoptosis in neuroblastoma cells requires mitochondrial activation and is inhibited by FLICE inhibitor proteins and bcl-2. Cancer Res 2001; 61: 4864-4872.

25 van Noesel MM, Pieters R, Voute PA, Versteeg R. The N-myc paradox: N-myc overexpression in neuroblastomas is associated with sensitivity as well as resistance to apoptosis. Cancer Lett 2003; 197: 165-172.
26 Eggert A, Grotzer MA, Zuzak TJ, Wiewrodt BR, Ho R, Ikegaki N et al. Resistance to tumor necrosis factor-related apoptosis-inducing ligand-induced apoptosis in neuroblastoma cells correlates with a loss of caspase-8 expression. Cancer Res 2001; 61: 1314-1319.

27 Van Noesel MM, Van Bezouw S, Salomons GS, Voute PA, Pieters R, Baylin SB et al. Tumor-specific down-regulation of the tumor necrosis factor-related apoptosis inducing ligand decoy receptors DcR1 and DcR2 is associated with dense promoter hypermethylation. Cancer Res 2002; 62: 2157-2161.

28 Sheard MA, Asgharzadeh S, Liu Y, Lin TY, Wu HW, Ji L et al. Membrane-bound TRAIL supplements natural killer cell cytotoxicity against neuroblastoma cells. J Immunother 2013; 36: 319-329.

29 Ammann JU, Haag C, Kasperczyk H, Debatin K-M, Fulda S. Sensitization of neuroblastoma cells for TRAIL-induced apoptosis by NF-kB inhibition. Int J Cancer Res 2009; 124: 1301-1311.

30 Opel D, Naumann I, Schneider M, Bertele D, Debatin K-M, Fulda S. Targeting aberrant PI3K/Akt activation by $\mathrm{PI} 103$ restores sensitivity to TRAIL-induced apoptosis in neuroblastoma. Clin Cancer Res 2011; 17: 3233-3247.

31 Gatsinzi T, Iverfeldt K. Sensitization to TRAIL-induced apoptosis in human neuroblastoma SK-N-AS cells by NF- $K B$ inhibitors is dependent on reactive oxygen species (ROS). J Neurooncol 2011; 104: 459-472.

32 Wang M-J, Liu S, Liu Y, Zheng D. Actinomycin D enhances TRAIL-induced caspasedependent and -independent apoptosis in SH-SY5Y neuroblastoma cells. Neurosci Res 2007; 59: 40-46.

33 Muhlethaler-Mottet A, Balmas Bourloud K, Auderset K, Joseph J-M, Gross N. Drug-mediated sensitization to TRAlL-induced apoptosis in caspase-8complemented neuroblastoma cells proceeds via activation of intrinsic and extrinsic pathways and caspase-dependent cleavage of XIAP, Bcl-xL and RIP. Oncogene 2004; 23: 5415-5425.

34 Naumann I, Kappler R, von Schweinitz D, Debatin K-M, Fulda S. Bortezomib primes neuroblastoma cells for TRAIL-induced apoptosis by linking death receptor to the mitochondrial pathway. Clin Cancer Res 2011; 17: 3204-3218.

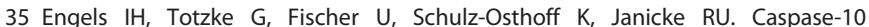
sensitizes breast carcinoma cells to TRAIL-induced but not tumor necrosis factor-induced apoptosis in a caspase 3-dependent manner. Mol Cell Biol 2005; 25: $2808-2818$

36 Shenoy K, Wu Y, Pervaiz S. LY303511 enhances TRAIL sensitivity of SHEP-1 neuroblastoma cells via hydrogen peroxide-mediated mitogen-activated protein kinase activation and up-regulation of death receptors. Cancer Res 2009; 69: 1941-1950.

37 Kim HR, Lee MW, Kim DS, Jo HY, Lee SH, Chueh HW et al. Etoposide sensitizes neuroblastoma cells expressing caspase 8 to TRAIL. Cell Biol Int Rep 2011; 19: 23-30.

38 Flahaut M, Muhlethaler-Mottet A, Auderset K, Balmas Bourlaoud KB, Meier R, Popovic MB et al. Persistent inhibition of FLIPL expression by lentiviral small hairpin RNA delivery restores death-receptor-induced apoptosis in neuroblastoma cells. Apoptosis 2006; 11: 255-263.

39 Chang DW, Xing Z, Pan Y, Algeciras-Schimnich A, Barnhart BC, Yaish-Ohad S et al. c-FLIPL is a dual function regulator for caspase-8 activation and CD95-mediated apoptosis. EMBO J 2002; 21: 3704-3714.

40 Tong HX, Lu CW, Zhang JH, Ma L, Zhang JH. Combination of gamma-interferon with TRAIL and cisplatin or etoposide induces apoptosis in human neuroblastoma cell line SH-SY5Y. Chin Med Sci J 2007; 22: 38-43.

41 Camoratto AM, Jani JP, Angeles TS, Maroney AC, Sanders CY, Murakata C et al. CEP-751 inhibits Trk receptor tyrosine kinase activity in vitro exhibits anti-tumor activity. Int J Cancer 1997; 72: 673-679.

42 Behrens MM, Strasser U, Choi DW. Go $\$ 976$ is a potent inhibitor of neurotrophin-receptor intrinsic tyrosine kinase. J Neurochem 1999; 72: 919-924.

43 Wood ER, Kuyper L, Petrov KG, Hunter RN, Harris PA. Discovery and in vitro evaluation of potent TrkA kinase inhibitors: oxindole and aza-oxindoles. Bioorg Med Chem Lett 2004; 14: 953-957.

44 Cunningham ME, Stephens RM, Kaplan DR, Greene LA. Autophosphorylation of activation loop tyrosines regulates signaling by the TRK nerve growth factor receptor. J Biol Chem 1997; 272: 10957-10967.

45 Kozopas KM, Yang T, Buchan HL, Zhou P, Craig RW. MCL1, a gene expressed in programmed myeloid cell differentiation, has sequence similarity to BCL2. Proc Natl Acad Sci USA 1993; 90: 3516-3520.

46 Henson ES, Gibson EM, Villanueva J, Bristow NA, Haney N, Gibson SB. Increased expression of $\mathrm{Mcl}-1$ is responsible for the blockage of TRAIL-induced apoptosis mediated by EGF/ErbB1 signaling pathway. J Cell Biochem 2003; 89: 1177-1192.

47 Liu H, Yang J, Yuan Y, Xia Z, Chen M, Xie L et al. Regulation of Mcl-1 by constitutive activation of NF-KB contributes to cell viability in human esophageal squamous cell carcinoma cells. BMC Cancer 2014; 14: 98.

48 Nguyen TB, Livolsi A, Peyron JF, Prehn JH. Activation of nuclear factor KB and $b c l-x$ survival gene expression by nerve growth factor requires tyrosine phosphorylation of IkBa. J Cell Biol 2001; 152: 753-764. 
49 Farina AR, Masciulli MP, Tacconelli A, Cappabianca L, De Santis G, Gulino A et al. All-trans-retinoic acid induces nuclear factor kappaB activation and matrix metalloproteinase-9 expression and enhances basement membrane invasivity of differentiation-resistant human SK-N-BE 9N neuroblastoma cells. Cell Growth Differ 2002; 13: 343-354.

50 Schreck R, Meier B, Mannel DN, Droge W, Baeuerle PA. Dithiocarbamates as potent inhibitors of nuclear factor kappa B activation in intact cells. J Exp Med 1992; 175: 1181-1194.

51 Zhang XD, Franco AV, Nguyen T, Gray CP, Hersey P. Differential localization and regulation of death and decoy receptors for TNF-related apoptosisinducing ligand (TRAIL) in human melanoma cells. J Immunol 2000; 164: 3961-3970.

52 Moubarak RS, Solè C, Pascual M, Gutierrez H, Llovera M, Perez-Garcia MJ et al. The death receptor antagonist FLIP-L interacts with Trk and is necessary for neurite outgrowth induced by neurotrophins. J Neurosci 2010; 30: 6094-6105.

53 Kantari C, Walczak H. Caspase- 8 and Bid: caught in the act between death receptors and mitochondria. Biochim Biophys Acta 2011; 1813: 558-563.

54 Grambihler A, Higuchi H, Bronk SF, Gores GJ. cFLIP-L inhibits p38 MAPK activation: an additional anti-apoptotic mechanism in bile acid-mediated apoptosis. J Biol Chem 2003; 278: 26831-26837.

55 Garcia-Calvo M, Peterson EP, Leiting B, Ruel R, Nicholson DW, Thornberry NA Inhibition of human caspases by peptide based and macromolecular inhibitors. J Biol Chem 1998; 273: 32608-32613.

56 Lawrence $C P$, Chow SC. Suppression of human T cell proliferation by the caspase inhibitors, z-VAD-FMK and z-IETD-FMK is independent of their caspase inhibition properties. Toxicol Appl Pharmacol 2012; 265: 103-112.

57 Özören N, Kim K, Burns TF, Dicker DT, Moscioni AD, El-Deiry DS. The caspase 9 inhibitor Z-LEHD-FMK protects human liver cells while permitting death of cancer cells exposed to tumor necrosis factor-related apoptosis-inducing ligand. Cancer Res 2000; 60: 6259-6265.

58 Zhang XD, Zhang XY, Gray CP, Nguyen T, Hersey P. Tumor necrosis factor-related apoptosis-inducing ligand-induced apoptosis of human melanoma cells is regulated by Smac/Diablo release from mitochondria. Cancer Res 2001; 61: 7339-7348.

59 van Loo G, van Gurp M, Depuydt B, Srinivasula SM, Rodriguez I, Alnemri ES et al. The serine protease Omi/HtrA2 is released from mitochondria during apoptosis. Omi interacts with caspase-inhibitor XIAP and induces enhanced caspase activity. Cell Death Differ 2002; 9: 20-26.

60 Bui NT, Livolsi A, Peyron JF, Prehn JH. Activation of nuclear factor kappaB and $\mathrm{Bcl}-\mathrm{x}$ survival gene expression by nerve growth factor requires tyrosine phosphorylation of Ikappa B alpha. J Cell Biol 2001; 152: 753-764.

61 Catz SD, Johnson JL. Transcriptional regulation of bcl-2 by nuclear factor kappa B and its significance in prostate cancer. Oncogene 2001; 20: 7342-7351.

62 Riccio A, Ahn S, Davenport CM, Blendy JA, Ginty DD. Mediation by a CREB family transcription factor of NGF-dependent survival of sympathetic neurons. Science 1999; 286: 2358-2361.
63 Grimes CA, Jope RS. CREB DNA binding activity is inhibited by glycogen synthase kinase-3 beta and facilitated by lithium. J Neurochem 2001; 78: 1219-1232.

64 Poluha W, Poluha DK, Ross AH. TrkA neurogenic receptor regulates differentiation of neuroblastoma cells. Oncogene 1995; 10: 185-189.

65 Tacconelli A, Farina AR, Cappabianca L, Desantis G, Tessitore A, Vetuschi A et al. TrkA alternative splicing: a regulated tumor-promoting switch in human neuroblastoma. Cancer Cell 2004; 6: 347-360.

66 Malerba F, Paoletti F, Bruni Ercole B, Materazzi S, Nassini R, Coppi E et al. Functional characterization of human ProNGF and NGF mutants: identification of NGF P61SR100E as a "painless" lead investigational candidate for therapeutic applications. PLoS One 2015; 10: e0136425.

67 von Karstedt S, Conti A, Nobis M, Montinaro A, Hartwig T, Lemke J,? et al. Cancer cell-autonomous TRAIL-R signaling promotes KRAS-driven cancer progression, invasion, and metastasis. Cancer Cell 2015; 27: 1-13.

68 Moley JF, Brother MB, Wells SA, Spengler BA, Biedler JL, Brodeur GM. Low frequency of ras gene mutations in neuroblastomas, pheochromocytomas, and medullary thyroid cancers. Cancer Res 1991; 51: 1596-1599.

69 Ballas K, Lyons J, Janssen JWG, Bartram CR. Incidence of ras gene mutation in neuroblastoma. Eur J Pediatr 1998; 147: 313-314.

70 Eleveld TF, Oldridge DA, Bernard V, Koster J, Colmet Daage L, Diskin SJ et al. Relapsed neuroblastomas show frequent RAS-MAPK pathway mutations. Nat Genet 2015; 47: 864-871.

71 Zazzeroni F, Papa S, Algeciras-Schimnich A, Alvarez K, Melis T, Bubici C et al. Gadd45 beta mediates the protective effects of CD40 co-stimulation against Fas-induced apoptosis. Blood 2003; 102: 3270-3279.

72 Schindelin J, Rueden CT, Hiner MC, Eliceiri KW. The ImageJ ecosystem: an open platform for biomedical image analysis. Mol Reprod Dev 2015; 82: 518-529.

73 Ribble D, Goldstein NB, Norris DA, Shellman YG. A simple technique for quantifying apoptosis in 96-well plates. BMC Biotechnol 2005; 5: 12-18.

74 Baskic D, Popovic S, Ristic P, Arsenijevic NN. Analysis of cycloheximide- induced apoptosis in human leukocytes: fluorescence microscopy using annexin V/propidium iodide versus acridine orange/ethidium bromide. Cell Biol Int 2006; 30 : 924-932.

75 Sprick MR, Weigand MA, Rieser E, Rauch CT, Juo P, Blenis J, Krammer PH et al. FADD/MORT1 and caspase- 8 are recruited to TRAIL receptors 1 and 2 and are essential for apoptosis mediated by TRAIL receptor 2. Immunity 2000; 12: 599-609.

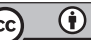

This work is licensed under a Creative Commons Attribution 4.0 International License. The images or other third party material in this article are included in the article's Creative Commons license, unless indicated otherwise in the credit line; if the material is not included under the Creative Commons license, users will need to obtain permission from the license holder to reproduce the material. To view a copy of this license, visit http://creativecommons.org/licenses/ by/4.0/ 